Anuario de Estudios Medievales

43/2, julio-diciembre de 2013, pp. 609-647

ISSN 0066-5061

doi:10.3989/aem.2013.43.2.04

\title{
EL PAPA URBANO II Y EL ORIGEN DE LA GARCINEIDA ${ }^{1}$
}

\section{POPE URBAN II AND THE ORIGIN OF THE GARCINEIDA}

\author{
ALBERTO GONZÁLEZ GARCÍA \\ Universidad Complutense de Madrid
}

\begin{abstract}
Resumen: Este trabajo pretende revisar las más recientes investigaciones académicas sobre la sátira latina del siglo XI llamada Garcineida, a fin de determinar su origen, autoría y credibilidad. El análisis de esta obra, así como de otras fuentes primarias y secundarias, nos lleva a dos interesantes conclusiones. Primero, a rechazar la teoría de un origen alemán y apreciar lo plausible de un origen hispánico cluniacense. En segundo lugar, planteamos la existencia de hechos que contrarían la imagen de Urbano II como un reformador inmaculado y permiten constatar que, a pesar de su virulencia, la susodicha sátira se basaba en una realidad.
\end{abstract}

Palabras clave: Urbano II; Garcineida.

\begin{abstract}
This paper aims to re-examine the most recent scholarly work on the eleventh-century Latin satire known as Garcineida, in order to determine its origin, authorship and credibility. The analysis of this work, as well as other primary and secondary sources, leads us to two interesting conclusions. First, we reject the theory of a German original, and we suggest the plausibility of a Spanish-Cluniac origin. In second place, the existence of facts that contradict the image of Urban II as a faultless reformer is outlined. They allow to verify that, despite its virulence, the aforesaid satire was based on reality.
\end{abstract}

Keywords: Urban II; Garcineida.

\section{SUMARIO}

1. Introducción.- 2. Origen de las copias conservadas.- 3. Urbano II y Cluny.-4. La corrupción pontificia.- 5. ¿Autoría germánica?.- 6. ¿Realidad o ficción?.- 7. ¿Autoría hispánica?.- 8. ¿Autoría francesa?.- 9. Conclusiones.- 10. Bibliografía citada.

1 El presente estudio se basa en una comunicación previa, Origen y autoría de la Garcineida: el descontento de la Iglesia Hispana con Roma, presentada en las I Xornadas de Novos Investigadores (Orense, 16-17 de noviembre de 2011). Abreviaturas utilizadas: $M G H=$ Monиmenta Germaniae Historica; $P L=$ Patrologia Latina. 


\section{INTRODUCCIÓN}

La llamada Garcineida -en feliz expresión de María Rosa Lida de Malkiel- es una formidable sátira en latín que denuncia la corrupción de la Curia Pontificia en época de Urbano II (1088-1099), el célebre predicador de la Primera Cruzada, pintando una demoledora escena de gula, venalidad y avaricia, tan grotesca como divertida. Sin duda es una de las obras más curiosas y enigmáticas del siglo XI.

Narra cómo el arzobispo de Toledo, Grimoardus (trasunto de Bernardo de Sauvetat, 1086-1124) llevó a Roma las reliquias de los santos Albino y Rufino (oro y plata en abundancia) en la primavera de 1099, a fin de comprar la legación papal para Aquitania. Recibido con jactanciosos discursos alabando el poder del dinero, un opíparo banquete y una no menos formidable borrachera, el Papa y sus cardenales constataron que el toledano era tan crápula como ellos mismos, decidiendo atender favorablemente a su ruego. Le acompañaba en todo momento uno de sus canónigos, el socarrón García, testigo, narrador y crítico de todo ello.

En 2001, y tras ser objeto de diversas ediciones y estudios, Maurilio Pérez González, catedrático de Filología Latina en la Universidad de León, realizó una espléndida edición crítica con traducción. A pesar de todas sus evidentes virtudes, el estudio histórico y las conclusiones respecto al origen y autoría de la Garcineida no tienen la misma calidad y rigor que el resto de su obra. Contienen -a nuestro entender- algunos errores factuales y de interpretación, que servirán de hilo conductor a nuestro discurso ${ }^{2}$.

2 J. von Pflugk-Harttung, Iter Italicum, pp. 439-452 y 729; K. Francke, MGH Ldl 2, pp. 423-435; L. Paulot, Un pape français, pp. 223-227; P.J.G. Lehmann, Die Parodie, pp. 45-50; M.R. Lida, Garcineida; E.J. Weber, Comedy as Satire; J.A. Yunck, The Lineage, pp. 71-5; F. Rico, Letras latinas del siglo XII, pp. 42 y 49-50; M.C. Díaz, Escritores eclesiásticos, p. 854; R.M. Thomson, Tractatus Garsiae; R. García-Villoslada, La poesía de los goliardos, pp. 117 y 308-316; J. Barreiro, Ideología y conflicto de clases, pp. 162-175; J.L. Moralejo, Literatura hispano-latina, pp. 67-68; J.J. Cienfuegos, La Garcineida; J.L. Moralejo, Latín y cultura, p. 14; J.J. Cienfuegos, El aparte del teatro; S. Bodelón, Literatura latina, pp. 78-80; M.A. Fornés, Enunciació i estil a la Garcineida; E. Benito, J.A. Villar, Garcineida; A. Higashi, Revisitación; M. Pérez, Religión y política; M. Pérez, Garcineida; F. Dolbeau, Maurilio Pérez; A. Higashi, Horacio lírico; F. González, Maurilio Pérez; R. Wright, La "Garcineida"; L. Charlo, Maurilio Pérez; M. Pérez, De nuevo sobre la Garcineida; A. Higashi, Tendencias en la edición, pp. 265280; S. Bodelón, Maurilio Pérez; C. Codoñer, Reforma gregoriana. 


\section{ORIGEN DE LAS COPIAS CONSERVADAS}

El códice A, preservado en la Biblioteca Vaticana, es un misceláneo alemán del siglo XIV. La copia de la Garcineida que contiene está escrita en letra carolina del $\mathrm{XII}^{3}$. El B, también conservado en la Biblioteca Vaticana, es otro misceláneo de comienzos del siglo XIV y originario de Cluny. Contiene la copia de la crónica de un monje del XII, que intercaló la Garcineida en su propia obra ${ }^{4}$.

El primero procede del monasterio agustino de Frankenthal (Renania), hecho considerado por Maurilio Pérez un argumento decisivo a la hora de postular la autoría germánica de la obra que nos ocupa. Desconocemos por qué le merece tanta seguridad, ya que el mismo cuadernillo contiene cuatro cartas coetáneas del obispo Ivo de Chartres (1090-1115), y el códice incluye otras numerosas obras de clara autoría no germánica, como una Vida de Santa María Egipcíaca en hexámetros leoninos o una Psychomachia de Prudencio, en carolina del XI y el XII.

Frankenthal, fundado en 1119, poseía un renombrado scriptorium con gran tráfico de manuscritos. El siglo XIV fue su momento de mayor esplendor. Por tanto, la presencia de una copia de la Garcineida no es, en modo alguno, un argumento que permita atribuir un origen alemán a la obra. $\mathrm{Ni}$ siquiera al cuadernillo que la contiene. Cabe señalar que Frankenthal está a unos $500 \mathrm{~km}$ de Cluny, remontando el valle del Saona y descendiendo por el del Rin. No sería extraño que una copia cluniacense hubiera llegado a ese monasterio, aunque pertenecieran a distinta orden.

Los códices G y T incluyen sendas copias de la Garcineida en letra carolina de la primera y la segunda mitad del siglo XII, insertas entre otras obras misceláneas de distintas épocas y procedencias. Considerados ingleses por Maurilio Pérez, son -en realidad- franceses, como ya advertía Rodney Thomson ${ }^{5}$. Casi obvia recordar que los reyes de Inglaterra procedían de Normandía y Anjou, y dominaban más de media Francia en aquellas fechas.

El G ${ }^{6}$ fue, al parecer, propiedad de William Grey (c. 1410-1478), obispo de Ely y Canciller de Oxford, tesorero de Eduardo IV, que pasó largos años en Italia y estuvo al servicio del cardenal Bessarion. Según una anotación del propio códice, el poco escrupuloso obispo Grey se lo sustrajo a los monjes benedictinos de Canterbury?

3 Vaticanus Palatinus latinus, 242, ff. 63v-70v, cf. M. Pérez, Garcineida, pp. 169-171.

4 Vaticanus Reginensis latinus, 1911, ff. 91v-95v, cf. M. Pérez, Garcineida, pp. 171-173.

5 R.M. Thomson, Tractatus Garsiae, p. 9.

6 Gonville and Caius College 427, ff. 134v-143v, cf. M. Pérez, Garcineida, pp. 173-174.

7 J.J. Smith, Catalogue, vol. I, pp. 205-206: "Hic Monachus Canuarensis libere vellicat insolentiam Willimi Ep. Eliens. Cancellarii Anglie sub Rege Richo, cuius mores Histriographi ad plenux depinxerunt". 
El $\mathrm{T}^{8}$ contiene un singular tratado de conjugación francesa -escrito en latín- que ocupa los ff. 47v y 48r del mismo, también en letra carolina, como la copia de la Garcineida, pero algo posterior ${ }^{9}$. Su propiedad puede rastrearse hasta John Parker, hijo del capellán de Ana Bolena y arzobispo de Canterbury, Matthew Parker (1559-75), quien, presumiblemente, se apoderó del mismo -al igual que del resto de su colección de libros- a raíz de la Disolución de los Monasterios ${ }^{10}$.

Así pues, resulta razonable deducir un origen común francés para todo el conjunto de copias conservadas. Al fin y al cabo, Francia fue la patria de la literatura goliárdica, precursora de la cual fue la Garcineida ${ }^{11}$. Los manuscritos están emparentados a pares (AB, por un lado, y GT, por otro), pero todos ellos son copias independientes, lo que permite sospechar que en el siglo XII circularon numerosas copias de la obra ${ }^{12}$.

Concretando, lo más lógico es suponer que fuera cluniacense, ya que el códice B contiene la copia más antigua, de mediados del siglo XII. Como hemos comentado, fue incluida -no por casualidad- tras la crónica de un tal Richardus, monachus Cluniacensis, hecho que ha pasado desapercibido a pesar de su importancia. El tal Ricardo no es otro que Ricardo el Pictaviense (c. 1110-1173), el único historiador francés del siglo XII de obediencia estrictamente cluniacense ${ }^{13}$. Es interesante observar que el copista que amplió su Chronica en el Codex Parisiensis 5014 cometió la misma errata que figura en las copias A, B y T de la Garcineida, al llamar Ioannes Gaditanus a Juan de Gaeta (Ioannes Gaetanus) ${ }^{14}$.

Es decir, la Garcineida llegó al scriptorium de Cluny y fue considerada por un copista cluniacense digna de incorporarse a la obra de un compañero de hábito. Si no fue cosa del propio Pictaviense, claro está. Concretamente, fue intercalada entre su Chronica de diuersis libris collecta y otro opúsculo ajeno, De destructione castri Iulii, seguido por su catálogo de papas. Además, el copista agregó a la crónica de Ricardo, después de la mención a la muerte del rey Fulco de Jerusalén (1143), una mínima biografía de Hugo de Orleáns,

8 Trinity College R.3.56 ff. 37-44, cf. M. Pérez, Garcineida, pp. 174-176.

9 P. Meyer, Manuscrits français de Cambridge, pp. 65-67.

10 S. Strongman, John Parker's Manuscripts.

11 R. García-Villoslada, La poesía de los goliardos, pp. 41-44 y 308-309; M. Pérez, Garcineida, pp. 66-67.

12 M. Pérez, Garcineida, pp. 189-211.

13 B. Guenée, Histoire, p. 47. No existe una edición completa de sus obras. Su crónica puede hallarse en G. Waitz, MGH SS 26, pp. 74-84. Cf. É. Berger, Notice sur Divers Manuscrits, pp. 45-140; I. Schnack, Richard von Cluny; H. Kühl, Zur Überlieferung.

14 G. Waitz, MGH SS 26, p. 80; M. Pérez, Garcineida, pp. 274-275 y 319-320. Quizá un análisis más minucioso, fuera de nuestra capacidad, podría sacar más cosas en claro. 
el Primate Aurelianense, y unos versos leoninos donde también se menciona con sarcasmo al Romano Pontífice ${ }^{15}$ :

De Hugone lo Primat Aurelianensi.

"Hoc indumentum tibi quis dedit? An fuit emptum?

Estne tuum?" - "Nostrum, sed qui dedit abstulít ostrum.

Qui dedit hoc munus, dedit hoc in munere funus.

Qui dedit hoc munus, presul mihi prebuit unus,

Pontificum spuma, sex cleri, sordida struma,

Qui dedit in bluma mihi mantellum sine pluma.

Pauper mantelle, macer, absque pilis, sine pelle,

Si potes, expelle boream rabiemque procelle!

Sis mihi pro scuto, ne friigore pungar acuto!

Per te namque puto ventis obsistere tuto". -

Tunc ita mantellus: "Mihi nec pilus est neque vellus,

Si notus iratus patulos perflabit hyatus,

Stringet utrumque latus per mille foramina flatus.

Scid quid agis, Primas? Eme pelles, obstrue rimas.

Tunc bene depellam iuncta michi pelle procellam.

Compatior certe, moveor pietate super te

Et facerem iussum, sed Jacob, non Esau sum".

Parece claro, por tanto, el vínculo entre la Garcineida y el primer goliardo, a través de Cluny, sin que podamos determinar si la primera influyó en el segundo. Ambas obras se leyeron y divulgaron en ambientes cluniacenses, y fueron juzgadas importantes por el copista cuya labor acabó incluida en el Vaticanus Reginensis latinus 1911.

Estimamos que debe rechazarse la teoría de Lida de Malkiel, que circunscribía el texto a los conflictos entre la Iglesia Hispana y los reformistas cluniacenses, a raíz de la introducción del rito romano y prelados franceses en España, superados en época de Urbano $\mathrm{II}^{16}$. Ya M.C. Díaz y Díaz sugirió que la autoría de la Garcineida debía buscarse en un clérigo franco, una idea de la que se hizo eco Alejandro Higashi. Maurilio Pérez admitía la posibilidad de que fuera obra de un cluniacense reaccionario, favorable a las tesis del Papa (...), pero tan intransigente como descontento con la flexibilidad de Urbano II o con la debilidad mostrada por Pascual II. Sin embargo, la desdeñaba por considerar que ni es lógica ni le hace justicia al papa Urbano II, prometiendo revisarla en un futuro de acuerdo a otros textos medievales ${ }^{17}$. En espera de la

15 G. Waitz, MGH SS 26, p. 81-82, cf. F. Cairns, The Addition to Richard of Poitiers. Sobre Hugo, cf. R. García-Villoslada, La poesía de los goliardos, pp. 66-78; A.G. Rigg, Golias; F. Adcock, Hugh Primas and the Archpoet, pp. xvii-xxii.

16 M.R. Lida, Garcineida, pp. 250-251; M. Pérez, Garcineida, pp. 87-88.

17 M.C. Díaz, Escritores eclesiásticos, col. 854; M. Pérez, Garcineida, pp. 11 y 92-93. 
publicación de este estudio filológico, veamos cuán lógica es y cómo se ajusta a la realidad histórica.

A este respecto, Carmen Codoñer ya ha argumentado que los elementos internos de la obra permiten atribuir la autoría a un clérigo francés vinculado con España ${ }^{18}$.

\section{URBANO II Y CLUNY}

Resulta muy llamativa la incorporación de la Garcineida a la obra de Ricardo el Pictaviense, un cluniacense, y la difusión de la obra en el siglo XII. Tratándose de una sátira tan feroz de la Curia Romana, ¿cómo es posible? ¿No eran cluniacenses, todos ellos, probos reformadores y los mayores enemigos de la simonía? ¿Es que no había una absoluta sintonía entre los gregorianos y la abadía de Cluny, de la cual fue prior Urbano II? ¿Cómo podemos pensar en un cluniacense que arremete contra otros cluniacenses? ${ }^{19}$

Mitos pseudohistóricos aparte, lo cierto es que las cosas no eran tan simples. Cluny tenía admiradores y aliados en ambos bandos de la Querella de las Investiduras, ya que todos, papistas e imperialistas, afirmaban combatir la corrupción eclesiástica. Sus relaciones con Roma no fueron siempre amigables, y jamás estuvieron exentas de recelos y luchas de poder. Hugo el Grande no apoyó el extremismo gregoriano, y trató de negociar entre el Papado y el Imperio. Los cluniacenses tampoco se ceñían a un dogma monolítico, sino que existían diferentes pareceres en el seno de la propia Orden ${ }^{20}$.

Así por ejemplo, Bernardo de Cluny criticó amargamente al clero en general, y a la Curia en concreto, en su largo poema De contemptu mundi. Pero no tuvo empacho en dedicar la obra a su abad, Pedro el Venerable ${ }^{21}$.

De hecho, algún cluniacense podía tener motivos para sentirse descontento con Urbano II, traicionado por su antiguo compañero de hábito. Si algo se critica en la Garcineida es, precisamente, que el Papa abandonara la antigua sobriedad (veterem sobrietatem) y se convirtiera en un nuevo hombre

18 C. Codoñer, Reforma gregoriana.

19 M. Pérez, Garcineida, p. 85. Sobre Urbano II, $c f$. J.P. Migne, PL 151, col. 9-282; L. Paulot, Un pape; A. Becker, Papst Urban II. Sobre Bernardo, $c f$. J.F. Rivera, El arzobispo de Toledo Don Bernardo de Cluny.

20 Sobre las relaciones entre Cluny, los reformistas romanos y la Querella de las Investiduras, $c f$. H.E.J. Cowdrey, Cluniacs; G. Constable, The Abbey of Cluny, pp. 19-41, 81-111 y 179-189. Sobre el reformismo del siglo XI y los cluniacenses puede hallarse bibliografía y recursos adicionales en C. Sereno, Le diverse anime; idem, Cluny.

21 H.C. Hoskier, Bernard of Cluny; R.E. Pepin, Scorn for the World. 
(Urbanum novum hominem) ${ }^{22}$. Es decir, el autor reconoce que Urbano empezó con buen pie, pero acabó corrompiéndose.

Sus primeras cartas cruzadas con Cluny fueron extraordinariamente cordiales $^{23}$. En 1088 confirmó al abad Hugo diversas posesiones y privilegios, y le concedió el derecho de llevar vestimentas episcopales. La relación del Papa con su antiguo monasterio alcanzó su momento álgido el 18 de octubre de 1095, cuando Urbano consagró personalmente el altar mayor de la nueva iglesia abacial de Cluny ${ }^{24}$.

Sin embargo, en la Bula de Rottenbuch de 1092 -dirigida a canónigos que observaban la Regla de Aquisgrán-, Urbano II, aun reconociendo la pureza de la vida monástica, se pronunciaba a favor del clero secular, ya que consideraba que prácticamente se había extinguido ante la indiferencia popular, mientras los monasterios florecían ${ }^{25}$.

El Concilio de Melfi de 1089 prohibió que los abades recibieran regalos o exigieran un pago con ocasión de las conversiones o cualquier tipo de pacto, una práctica muy común en la época. Mandato ratificado en 1099, año de la Garcineida, que debió repercutir negativamente en los ingresos de Cluny, pues recibía cuantiosos regalos de este tipo ${ }^{26}$.

En 1090 y 1095-96 Urbano también bloqueó la agresiva expansión cluniacense (que forjó un verdadero imperio), al impedir la anexión de las abadías de Santa Fe de Conques y San Saturnino de Toulouse, importantes paradas en la vias Podiensis y Tolosana del Camino de Santiago francés (una de las capillas de la Catedral de Santiago aún está consagrada a Santa Fe). No parece que el privilegio de 1097, permitiendo a Cluny recibir a monjes y clérigos regulares, compensara gran $\operatorname{cosa}^{27}$, si bien apoyó su dominio sobre Limoges (centro de la llamada, precisamente, via Lemonicensis), llegando a deponer a su obispo ${ }^{28}$.

Además de atentar contra los ingresos abaciales, hay indicios que apuntarían a que el Romano Pontífice había contraído considerables deudas con Cluny. Ante su carencia de fondos, ocasionada por la pérdida del Patrimonio de

22 M. Pérez, Garcineida, pp. 268-269.

23 J.P. Migne, $P L$ 151, col. 284-285 y 291.

24 Ibidem, col. 291-293; H.E.J. Cowdrey, Cluniacs, pp. 58-61 y 178-180.

25 J.P. Migne, PL 151, col. 337-339, cf. H. Führmann, Papst Urban II.

26 G.D. Mansi, Sacrorum conciliorum, vol. 20, col. 723 y 964.

27 R. Sommerville, Urban II's Privilege.

28 N. Hunt, Cluny, pp. 124-185; O.K. Werckmeister, Cluny III, pp. 103-112. Es evidente el interés pecuniario de los cluniacenses por apoderarse de estos centros de peregrinaje y sus reliquias, que atraían enormes masas de gente y un flujo constante de dinero. En 1096 Hugo el Grande indicaba que muchos que querían peregrinar a Roma y no podían iban a Cluny, al ser casa del Papa (G. Constable, The Abbey of Cluny, pp. 28-29). 
San Pedro (vide infra), en 1088, el recién elegido Papa había rogado a Hugo de Cluny que le mandara alivio y consuelo en la hora de mayor necesidad de Roma. Una segunda carta requería al arzobispo Lanfranco de Canterbury que enviara directamente a Cluny, y tan rápido como fuera posible, el "Penique de Pedro", pagado por Inglaterra a la Sede Romana y que rentaba unos 300 marcos de plata ${ }^{29}$.

\section{LA CORRUPCIÓN PONTIFICIA}

La Garcineida nos presenta a un Urbano II corrupto y concupiscente, imagen que -a primera vista- parece difícil conciliar con su fama de reformista intachable. Resulta chocante ver al papa que promovió la Primera Cruzada, defendió con energía las prerrogativas del poder espiritual frente a las presiones imperiales y anatematizó la simonía y otras prácticas corruptas, atiborrarse de comida y vino, pedir sobornos con descaro y gritar Albinus vincit, Albinus regnat, Rufinus imperat ${ }^{30}$, parodiando la célebre aclamación a Cristo, convertida en grito de guerra de los cruzados.

La idea del carácter ficticio de la Garcineida se basa, en última instancia, en esta concepción tan benévola de Urbano II, beatificado por León XIII el 14 de julio de $1881^{31}$. Aunque el autor de la obra persiguiera una finalidad satírica o paródica, nos hemos de plantear si ello obedecía a una realidad histórica, en vez de quedarnos en el mero prejuicio sobre la beatitud y las bondades de este papa. Las cuales, de hecho, no son avaladas por las fuentes.

Urbano II se comprometió a seguir los pasos de Gregorio VII y promulgó, en efecto, reiteradas prohibiciones contra las investiduras laicas, la simonía y el nicolaísmo desde que sentó sus reales en la Cátedra de San Pedro, siendo las más célebres las de los concilios de Piacenza y Clermont, en 1095, que ratificaron los decretos de Gregorio, prohibiendo el vasallaje de obispos y clérigos para con reyes y otras personalidades seculares, y declararon inválidas todas las ordenaciones simoníacas ${ }^{32}$.

29 J. Ramackers, Analekten, p. 42; K. Jordan, Zur päpstlichen Finanzgeschichte, pp. 94-97. Sobre el "Penique de Pedro", $c f$. W.E. Lunt, Financial Relations, pp. 3-84.

30 M. Pérez, Garcineida, pp. 252-253.

31 E.g. R. García-Villoslada, La poesía de los goliardos, p. 309: "no conociendo bien al canónigo, no podemos explicar el por qué de la sátira contra su arzobispo (...), contra el dignísimo y virtuoso papa Urbano II y contra otros personajes de la curia romana"; M. Pérez, Garcineida, p. 87: "la caricatura de Urbano II y de la curia papal es tan notoriamente exagerada e injusta, incluso tratándose de una sátira, que a duras penas podría salir de la pluma de un clérigo hispano, habida cuenta de las relativamente tranquilas relaciones de la Iglesia española con la romana".

32 J.P. Migne, $P L$ 151, col. 284. Sobre su lucha contra la simonía, $c f$. L. Paulot, Un pape, pp. 147-167. 
Pero un simple examen superficial de las fuentes evidencia aparentes casos de soborno, favores y misteriosas absoluciones que parecen confirmar las peores sospechas de corrupción o, por lo menos, manifiestan la existencia de dudas razonables que alimentarían un clima de desconfianza y crítica hacia la presunta pureza del entonces Sumo Pontífice. Es decir, el caldo de cultivo crítico que produjo la Garcineida.

Debido a las turbulencias de la política coetánea, Urbano II pasó siete de sus once años de pontificado fuera de Roma. Estuvo en la Urbe a fines de 1088 y comienzos de 1089, pero hubo de refugiarse de nuevo en territorio normando. Aunque ese año obtuvo una victoria militar sobre 'Clemente III', que huyó a Tívoli, y logró entrar triunfal en Roma gracias a las armas normandas, el Antipapa y sus partidarios lograron el control total de la ciudad en 1091. Cuando volvió a Roma en noviembre de 1093, gracias al apoyo de Matilde de Toscana y el obispo de Milán, Urbano tuvo que acogerse a la seguridad de la fortaleza de la familia Frangipani, junto a la basílica de Santa María Nuova, en el Foro. En el verano de 1094 pasó a Toscana, invitado por la poderosísima condesa Matilde, y luego a Lombardía y a Francia, en busca de nuevos apoyos. No fue hasta 1096 que la amenaza de un ejército cruzado camino de Palestina, al mando de Hugo de Vermandois, hermano del Rey de Francia, devolvió a Urbano el control de la Urbe, entrando en la misma acompañado por Matilde. Aún así, el Antipapa conservó el dominio tanto del estratégico Castel Sant'Angelo como de la Basílica de San Pedro hasta 1098, permitiéndose incluso reunir un sínodo ${ }^{33}$. Sobornar a los levantiscos romanos era fundamental para conservar el control de la Urbe ${ }^{34}$.

El pontificado de Urbano II estuvo caracterizado, pues, por una constante emergencia económica, ya que el Patrimonio de San Pedro estuvo en manos de sus enemigos desde 1084, cuando Gregorio VII fue expulsado de Roma. Tras la deserción de muchos al bando del antipapa 'Clemente', incluyendo al canciller y el archidiácono, Urbano reconstruyó la administración pontificia, reorganizó la tesorería, y hasta creó un nuevo director financiero, el camerarius, cargo encomendado al monje cluniacense Pedro ${ }^{35}$.

Tan precaria llegó a ser su posición que el nuevo Papa, vistas las consecuencias de la intransigencia gregoriana, decidió combinar su rigidez

33 Cf. L. Paulot, Un pape, pp. 58-146, 292-311, 356-410 y 430-510; P. Kehr, Due documenti; R. Crozet, Le voyage de Urbain II; A. Becker, Papst Urban II, pp. 91-139 y 435-498; H. Houben, Urbano II.

34 I.S. Robinson, The Papacy, pp. 4-6.

35 Sobre la precariedad de la finanzas de Urbano II y la reconstrucción de la administración papal, cf. K. Jordan, Finanzgeschichte, pp. 61-104; D.B. Zema, Economic Reorganization; J. Sydow, Untersuchungen zur kurialen Verwaltungsgeschichte; I.S. Robinson, The Papacy, pp. 17-18 y $244-291$. 
en lo relativo a la supremacía papal con el realismo político para forjar un posibilismo conciliador, poniendo énfasis en la discreción y la flexibilidad ${ }^{36}$. Aunque es cierto que ya el propio Gregorio VII reconocía que la costumbre de la Iglesia Romana consiste en tolerar ciertas cosas y silenciar otras, siendo conveniente relajar los cánones $(1078)^{37}$, Giuseppe Fornasari ha señalado que el factor fundamental del pontificado de Urbano II fue precisamente el abandono necesario del radicalismo gregoriano, a fin de permanecer en el poder $^{38}$.

El propio Urbano II escribió en 1088 (aún en el exilio) a su colega benedictino el obispo Guimundo de Aversa (1088-1094), afirmando que era posible entenderse con pecadores y ladrones, pero no con los cismáticos seguidores de 'Clemente III' 39 . Ello a pesar de que no sólo no existía ninguna diferencia dogmática, sino que el Antipapa dejó recuerdo de hombre santo ${ }^{40}$.

Siendo tolerante con sus enemigos y algunos clérigos corruptos, el Papa logró ir ganando adeptos entre los leales a su adversario, obtener una posición ventajosa y volver a Roma. Según los extremistas gregorianos, cualquiera que tuviera trato con un clérigo excomulgado también estaba excomulgado. Sin rechazar este planteamiento, el nuevo Papa optó por ser dúctil, postergar decisiones difíciles y hacer uso y abuso de su derecho a suspender los cánones ${ }^{41}$. Así por ejemplo, Felipe I de Francia sólo fue excomulgado por su bigamia una vez Urbano hubo reforzado su propia posición.

Que todo dependiera del Sumo Pontífice se prestaba al abuso. Ya en 1075 había quejas a Gregorio VII, porque su supremacía judicial armaba a hijos contra padres y destruía la reverencia y la piedad ${ }^{42}$. En efecto, si alguien quería obtener una decisión inapelable, no había nada más fácil que sobornar a la Curia que asesoraba al Papa, y en la cual inevitablemente delegaba buena parte de su labor judicial. Urbano II se quejaba en 1096 de lo engorroso que le resultaba encargarse de las trivialidades que se sometían a su juicio ${ }^{43}$.

Se ha establecido que las sátiras contra la codicia papal tienen su origen e cambios en la estructura financiera de la Iglesia Romana ${ }^{44}$. Aunque Urbano pudiera obrar con la vista puesta en un bien mayor, ciertamente existe

36 L. Paulot, Un pape, pp. 75-79.

37 J.P. Migne, PL 148, col. 502.

38 G. Fornasari, Tra assestamento disciplinare.

39 J.P. Migne, PL 151, col. 357-358.

40 U. Longo, L. Yawn, Framing Clement III. Sobre la vida política y religiosa de este antipapa, $c f$. J. Ziese, Wibert von Ravenna.

${ }_{41}$ F. Gossman, Pope Urban II and Canon Law; S. Kuttner, Urban II; C. Rolker, Canon Law, pp. 44-47.

42 I.S. Robinson, Periculosus Homo, pp. 128-129.

43 I.S. Robinson, The Papacy, p. 183.

44 J.A. Yunck, Economic Conservatism. 
un trasfondo de dinero y poder que hace sospechar que, tal como denunciaba la Garcineida, Albino y Rufino abrían todas las puertas de Roma ${ }^{45}$. Según esta obra, sólo una vez Urbano se subió al carro de los simoníacos obtuvo la victoria sobre sus enemigos ${ }^{46}$ :

Hubo, hubo en el pasado días de ira, días de amargura, días de miseria, días de tempestad y de dolor, cuando teníamos tiempo para lamentarnos, cuando la sede romana se le negaba a Urbano, cuando el Senado no era nuestro, cuando, como huíamos de Enrique desterrados, cuando Guiberto se sentaba feliz y herético en la silla de San Pedro. Pero ahora, por la gracia de los santos mártires Albino y Rufino, hemos llegado a puerto después del naufragio, desde el exilio hemos regresado a la patria.

Así por ejemplo, cabe destacar, a este respecto, que en 1088 Urbano escribió al obispo de Montpellier indicándole que él y sus sucesores debían pagar una onza de oro al año, al igual que San Bartolomé de Lípari (1091) y Santa María Casinense (1093); San Antonio de Rodez debía pagar cinco sólidos (1090); Ripoll, un sólido (1091); Reinhardsborn, dos sólidos (1092), Hirsau, un sólido (1095), San Pedro de la Selva Negra, otro (1095); San Pierremont de Avril, otro más (1095); San Pedro de Bleffe, cinco sólidos (1095); Santa Escolástica de Juvingy-sur-Loison, seis argénteos (1096); Santa María de Buron (1098); San Martín de Wiblingen, un sólido (1098), Sant Cugat del Vallés, un morabetino (1098)...; todo ello por la libertad de la Iglesia Roma$n a^{47}$. En 1093 el Papa apremió a todo el clero del Sur de Francia enviarle fondos para la restauración de la libertad de la Sede Apostólica ${ }^{48}$. No podemos dejar de vincular estas peticiones con cierto fragmento de la Garcineida ${ }^{49}$ :

[Urbano] exhortaba de este modo (...): "Ea, ea, hijos de la Iglesia romana, entrañas de San Pedro, verdadero Israel, acercaos a hacer vuestra donación (...) Si alguien tiene reliquias de los dos mártires, acérquese sin temor y ofrézcalas; quienes no la tengan, que salgan fuera. Pues está escrito: 'Honra a Urbano con tus bienes y con las primicias de tus frutos' (...) Y cuando marchaban después de hecha la ofrenda, les añadía: "Ea, ea, hijitos míos (...), si os quedase algún resto (...) de los dos mártires, presentádnoslo pun-

45 Una chanza similar -nadie puede llamar a la puertas de Roma con las manos vacías- la encontramos en el Evangelium Secundum Marcas Argenti, cf. A. Hilka, O. Schumann, B. Bischoff, Carmina Burana, p. 86, y R. García-Villoslada, La poesía de los goliardos, p. 327.

46 M. Pérez, Garcineida, pp. 262-265.

47 J.P. Migne, PL 151, col. 293-294, 299-300, 319-320, 329-330, 342-343, 363-364, 402$404,404-406,419-420$ y $422-423,498-499,501-502$ y $513-515$.

48 Ibidem, col. 368-369.

49 M. Pérez, Garcineida, pp. 248-251. 
tualmente sabiendo que está escrito: "No te presentarás con las manos vacías en presencia del pontífice romano". Y en otro pasaje: "Urbano ama a quien da con alegría". Pues en esto conoceré si sois hijos míos, si me ofrecéis las preciadas reliquias.

Hemos recopilado casi una veintena de casos harto sospechosos, sin que pretendamos ofrecer un listado exhaustivo; una investigación más minuciosa probablemente hallará sucesos similares:

1) El arzobispo de Lyon, Hugo de Die (1083-1106), cuyo exceso de celo reformista le llevó a ser censurado por Gregorio VII (1075), acusó en el Concilio de Capua (1087) al futuro Urbano II de haber tolerado con cinismo la consagración anticanónica de Víctor III a fin de preservar su posición privilegiada. Excomulgado ese mismo año, fue rehabilitado en 1093, pero nunca tuvo buena relación con el Papa, declinando la legacía por considerar ocioso representar a una cabeza débil (languidum caput) como la suya. Fue el impulsor de la excomunión por bigamia del Rey de Francia en 1095, y en 1097 nuevamente reprendido por su intransigencia. Entregado a defender sus intereses e independencia de las intromisiones romanas, y no obstante sus ideales, comenzó a apoyarse en clérigos simoníacos como Norgardo de Autun, particular y notoriamente corrupto, pero muy astuto y bien relacionado con la Curia ${ }^{50}$.

2) En 1088, Jordán I, conde de Aversa y príncipe de Capua (1078-1091), pidió al recién coronado Urbano que anulara el matrimonio de su hija con Renaldo Ridel, duque de Gaeta. Lo cual logró mediante el simple juramento de que había sido coaccionado a consentir tal matrimonio $^{51}$. Junto con su primo Roberto Guiscardo, duque de Apulia y Calabria, había sido uno de los principales sostenes del Papado durante los pontificados de Gregorio VII y Víctor III ${ }^{52}$.

3) Otro de los grandes sostenes económicos del Papa fue el conde de Sicilia, Roger de Hauteville (futuro rey Roger II de Sicilia). Ya en 1088 Urbano se refería a él como dilectissimus filius noster Rogerus, y en 1092 le saludaba como charissimo filio nostro Rogerio comiti, Christianae fidei propugnatori, a causa de su lucha contra el Islam

50 P. Healy, The Chronicle of Hugh of Flavigny, pp. 19-21 y 75-81.

51 J.T. Noonan Jr., The Power to Choose, pp. 419-420.

52 Roberto Guiscardo prestó vasallaje al Papa en 1059, en 1083 envió nada menos que 30.000 sólidos para que recuperara el favor de los romanos (G.H. Pertz, MGH SS 5, p. 61), y en 1084 liberó personalmente a Gregorio VII tras una revuelta local, $c f$. L.I. Hamilton, Memory, Symbol, and Arson. 
en la isla ${ }^{53}$. Poco después, en 1095, arregló el matrimonio de una hija suya con Conrado, hijo rebelde del emperador Enrique IV.

4) En una carta al Patriarca de Constantinopla, el metropolitano Basileos de Reggio denunciaba que había sido expulsado y su sede entregada a un normando que había sobornado al Papa y al conde Roger con 10.000 nomismata $^{54}$.

5) La relación entre el Papado y el rey Sancho Ramírez de Aragón (106394) fue de lo más singular. Este monarca se declaró miles Beati Petri en un viaje a Roma en 1068. En 1071, durante la legacía de Hugo Cándido, cardenal presbítero de San Clemente, los tres principales monasterios aragoneses (San Juan de la Peña, San Victoriano y San Pedro de Loarre) se vincularon directamente a la Silla de San Pedro, pagando un censo anual ${ }^{55}$. En 1088, Sancho reconoció a Urbano II, se declaró feudatario suyo y se comprometió, él mismo y sus hijos, a pagar 500 mancusos de oro anuales a la Santa Sede mientras vivieran. En su respuesta, tras agradecerle el dinero, y cambiando radicalmente de tema, el Papa juzgaba un importante asunto planeado por el Rey: había prometido la mano de su sobrina a un caballero, pero decía haberlo hecho bajo presión, y la propia joven no aprobaba semejante matrimonio. Urbano no sólo le libraba de su compromiso, sino que se refería al rey aragonés con un tratamiento de compadreo absolutamente insólito, el de queridísimo amigo (que figura en una bula dirigida al abad de San Juan de la Peña) ${ }^{56}$.

6) En 1091, el obispo Gervino de Amiens (1091-1103) fue denunciado por su propio cabildo, imputado por haber adquirido su sede episcopal y la abadía benedictina de Saint-Riquier merced a la perversión simoníaca; sin embargo, tras acudir a Roma y jurar que tales acusaciones eran falsas, Urbano le confirmó en su sede, y en 1093 impidió realizar ulteriores investigaciones. Algo debían tener de cierto, puesto que, ante la magnitud del saqueo perpetrado, el propio Urbano hubo de apartarle de Saint-Riquier en 1095, aunque no de su sede episcopal ${ }^{57}$.

53 J.P. Migne, PL 151, col. 287 y 340.

54 W. Holtzmann, Die Unionsverhandlungen, p. 54.

55 Hugo Cándido, acusado en repetidas ocasiones de simonía, acabó convertido en enemigo de Gregorio VII y excomulgado en 1078, uniéndose a 'Clemente III', $c f$. H. Holkotte, Hugo Candidus.

56 Decretum Gratiani, c. 31, q. 2, c. 3; J.P. Migne, PL 151, col. 373-374: "Regem Sancium charissimum amicum nostrum ex nostra parte saluta, et comitissam sororem eius"; Judicium Urbani Papae; cf. K. Jordan, Zur Päpstlichen Finanzgeschichte, p. 79; P. Kehr, Cómo y cuándo; J.T. Noonan Jr., The Power to Choose, p. 421; A.I. Lapeña, Sancho Ramírez, pp. 73-112.

57 J.P. Migne, $P L$ 151, col. 335 y 362-363, cf. J.S. Ott, Urban Space. 
7) Herberto de Losinga, culto y probo prior en la abadía benedictina de Fécamp, en Normandía, fue, no obstante, uno de los más públicos y notorios simoniacos de su tiempo. Primero obtuvo el rico abadengo benedictino de Ramsey, en Inglaterra. En 1091 se hizo con la sede episcopal de Thetford, a cambio de la abultada suma de 1900 libras, así como el abadengo de Hyde para su padre, Roberto de Losinga, obispo de Hereford. Ante el escándalo formado, a finales de 1093 viajó a Roma, donde el Papa no sólo le absolvió por sus pecados, sino que le nombró legado para investigar al arzobispo de York, Tomás de Bayeux, por sus numerosos conflictos con el arzobispo de Canterbury, primado de Inglaterra. Casualmente, había sido el propio Tomás quien le había investido como obispo de Thetford. De vuelta a Inglaterra, Herberto sobreseyó la causa contra el Arzobispo, trasladó la sede episcopal a Norwich y empleó sus mal obtenidas rentas en construir la nueva catedral de esa ciudad, donde instaló a monjes benedictinos en vez de a clérigos seculares. Murió en 1119, colmado de riqueza y honores ${ }^{58}$.

8) Cuando Urbano II estaba acogido por los Frangipani, en 1093, visitó Roma Godofredo de Craon, abad cluniacense de la Trinidad de Vendôme, un ardiente defensor de la reforma eclesiástica. Aunque su visita se debía a asuntos de su monasterio, Godofredo vendió todas sus posesiones y entregó el dinero a Urbano. Con estos fondos el Papa pudo sobornar a Ferrucio, comandante de la guarnición dejada por el antipapa 'Clemente' en el Palacio Laterano, y hacerse con el control del mismo a comienzos de 1094. El generoso abad fue recompensado, al parecer, con el título de cardenal presbítero de Santa Prisca. Tomó parte en los concilios de Clermont (1095) y Saintes (1096), y extendió la hospitalidad de su monasterio al Papa durante su viaje por Francia. Al parecer, el pontífice le apreciaba tamquam unicum filium y, en una carta a Calixto II (1119-1124), el propio Godofredo indicaba explícitamente que había sido muy generoso en sus censos a Roma y esperaba ser retribuido por ello ${ }^{59}$.

9) El otro apoyo financiero gracias al cual se sobornó a la guarnición del Laterano fue Petrus Leonis, acaudalado hijo de un judío converso que ostentaba el título de consul Romanorum y controlaba la isla Tiberi-

58 E.M. Goulburn, H. Symonds, The Life, Letters, vol. I, pp. 68-97; I. Atherton, Norwich Cathedral, pp. 22-45; se conserva un De simoniaca haeresi carmen dedicado a Losinga (H. Böhmer, MGH Ldl 3, pp. 615-617).

59 J.P. Migne, PL 151, col. 125, y PL 157, col. 33-35; M. Stroll, Calixtus II, pp. 268-286. Sobre su promoción al cardenalato, $c f$. R. Hüls, Kardinäle, pp. 198-199. 
na y el Teatro de Marcelo. Administrador, consejero y diplomático de la máxima confianza, fue el encargado de negociar la coronación imperial de Enrique V en 1111 y de sobornar a los partidarios del antipapa 'Gregorio VIII' para que rindieran el Vaticano en 1120. Su sarcófago le calificaba de hombre sin igual, rico en dinero e hijos (vir fuit inmmensus quem proles gloria census sustulit in vita non sit ut alter ita). Urbano II falleció mientras estaba en su casa, en 1099, y él escribió un poema en su memoria, execrando al antipapa 'Clemente'. Su hijo, Pietro Pierleoni, fue monje en Cluny; Pascual II le promovió a cardenal diácono de San Cosme y San Damián en 1112 y Calixto II a cardenal presbítero de Santa María in Trastevere. Llegaría a ser elegido antipapa por el Segundo Concilio de Letrán, con el nombre de 'Anacleto II' (1130-1138) ${ }^{60}$.

10) En 1093, el arzobispo Guido de Vienne -futuro Calixto II- intentó apoderarse de una gran extensión de tierra del obispado de Grenoble, sufragáneo suyo, aduciendo derechos falsos. A fin de confirmar su propiedad del mismo y evitar el escándalo y castigo por su ignominiosa acción, Guido envió un emisario a Roma, encargado de sobornar a la Curia con 500 sólidos de oro. Es natural que considerara necesario hacerlo, puesto que Urbano había apoyado a los monjes benedictinos de San Andrés de Vienne en sus quejas contra su arzobispo. El ya mencionado Godofredo de Vendôme, que aún estaba en compañía del Papa, habló en favor suyo. Así, en 1094 Urbano II confirmó que las tierras usurpadas eran propiedad del Arzobispo, que reconoció y supo agradecer el savoir faire del abad de Vendôme. Pero, ante los crecientes excesos de Guido, en 1095 el Papa censuró sus actos -en un documento donde reconocía haberle consagrado a pesar de no tener la edad necesaria, contrariando los cánones- y restituyó las tierras al obispo de Grenoble. Guido, despechado, movilizó sus mesnadas y amenazó con secuestrar al Papa si no satisfacía sus demandas. En el Concilio de Clermont fue nuevamente reprendido, y Grenoble separado de su autoridad, a lo que reaccionó ocupando a la fuerza las tierras en disputa. Aún en 1097 el Papa tronaba por haber contemporizado con tan indeseable personaje; encomendó a Hugo de Lyon aplicar todas sus energías a poner freno a sus ambiciones -con tan poco éxito que acabaría sentado en la Cátedra de San Pedro ${ }^{61}$.

60 J.P. Migne, PL 151, col. 259; M. Stroll, Symbols As Power, pp. 95-105; M. Stroll, Calixtus II, pp. 147, 271-272 y 329.

61 J.P. Migne, PL 151, col. 128-129; M. Stroll, Calixtus II, pp. 15-33 y 272-274. 
11) En 1094, Fulco de Dammartin, obispo de Beauvais (1089-95), fue acusado de emplear asesinos y haber obtenido su sede episcopal gracias a los sobornos de su padre, el cual juró ante el Papa, junto con un canónigo de Beauvais, que tales cargos eran falsos. Absuelto, Urbano II llegó al extremo de impedir que el arzobispo de Reims, Reinaldo, reabriera la causa ese mismo año ${ }^{62}$.

12) En 1094, Humbaldo de Saint-Sèvère, obispo de Limoges (1087-95), fue acusado de simonía, renunció y peregrinó a Jerusalén. A su vuelta, y a falta de pruebas que demostraran su delito, el Papa decidió restaurarle en su sede ${ }^{63}$.

13) Por bula expedida el 16 de abril de 1095, Urbano II -a través de su chambelán, Juan de Gaeta, futuro Gelasio II- concedió a Pedro I de Aragón, hijo y sucesor de Sancho, el derecho de los diezmos y las primicias de las nuevas iglesias y las rescatadas a los musulmanes (salvo las catedrales). Pedro acababa de enviar una embajada a Roma con 1000 mancusos correspondientes a los últimos dos años del censo prometido por su padre ${ }^{64}$.

14) En 1095 el legado papal Gualterio de Albano logró que Guillermo II de Inglaterra reconociera a Urbano como legítimo papa a cambio de la promesa de que la Santa Sede no volvería a enviar legado alguno a su reino, a fin de poner coto a la corrupción, sin su permiso expreso. Así, Urbano se aseguró el cobro del "Penique de Pedro", impagado desde 1088, que, como hemos mencionado, había dado orden de enviar directamente a Cluny ${ }^{65}$.

15) Rompiendo este concordato, en 1095-1096 Urbano II encomendó a Jarento -abad de San Benigno de Dijon- reconciliar al Rey de Inglaterra con su hermano el duque de Normandía, Roberto Curthose, y reformar la Iglesia de Inglaterra, con el encargo expreso de reprochar al Rey la apropiación de rentas eclesiásticas y su tolerancia para con la simonía y el nicolaísmo. A fin de atajar esta intromisión, y mientras recibía amablemente al legado, Guillermo envió en secreto 10 marcos de oro al Papa. En efecto, Urbano envió a su propio sobrino, cuyo nombre no se menciona, a fin de anular la misión de Jarento. Ante tales hechos, el cronista y abad cluniacense Hugo de Flavigny, testigo

62 J.P. Migne, $P L$ 151, col. 127-128 y 378-379 y 388. Urbano había alabado a Reinaldo a comienzos de su pontificado, y confirmado diversos privilegios, $c f$. J.P. Migne, $P L$ 151, col. 309-311.

63 Ibidem, col. 551-552.

${ }^{64}$ A. Urbieto, Colección diplomática, pp. 160-161; M.R. Gutiérrez, Una bula de Urbano II.

65 G.H. Pertz, MGH SS 8, pp. 474-475, cf. F. Barlow, William Rufus, pp. 342-344. 
presencial de todo ello, se preguntaba a sí mismo, escandalizado, qué podía permanecía incólume ante el insaciable torbellino de la avaricia romana (Sed quid imperturbatum relinquit inexplebilis gurges Romanae avaritiae?). Desilusionado con los "reformistas", acabaría pasándose al bando de Enrique V, bajo la protección del obispo Ricardo II de Verdún. Es interesante observar que le unía una amistad indisoluble con uno de los más ardientes defensores de la reforma, el ya mencionado Hugo de Lyon, del cual renegó al saber de su alianza con simoníacos ${ }^{66}$.

16) En 1098 Urbano nombró al obispo Roberto de Mesina legado papal en Sicilia. La reacción del conde Roger fue tan violenta, arrestándolo mientras celebraba misa, que, tras entrevistarse personalmente, Urbano rectificó y le concedió la prebenda definitiva: la legacía papal perpetua y hereditaria sobre sus propios territorios, un privilegio inaudito que representaba la total claudicación de la superior autoridad pontificia sobre los poderes seculares: podía establecer nuevos obispados, cambiar sus límites, elegir obispos, recaudar las rentas de la Iglesia y juzgar asuntos eclesiásticos con toda la autoridad del propio Papa. A fin de garantizarla, en 1099 remitió al recién investido Pascual II 1000 sólidos, empleados en pagar mercenarios para dar caza a 'Clemente III' ${ }^{67}$.

17) El 18 de julio de 1098 el Papa concedió derechos de primacía al arzobispado de Salerno ante la petición expresa del duque de Apulia y Calabria, Rogerio "Borsa" (llamado así a causa de su avaricia), qui semper apostolicae sedi fideliter obsecutus est, al que había investido en el concilio de Melfi de $1089^{68}$.

18) Apenas un mes después (23 de agosto), el Papa logró tomar el Castel Sant'Angelo, hecho mencionado de pasada en la Garcineida, una vez más gracias al soborno, pagado precisamente con dinero de Apulia, Calabria y Sicilia ${ }^{69}$.

66 G.H. Pertz, MGH SS 8, p. 475, cf. F. Barlow, William Rufus, pp. 364-365; P. Healy, The Chronicle of Hugh of Flavigny, pp. 63-88. El mismo cronista denunciaba más adelante la rapacidad del clero romano en Normandía con idéntica expresión ("Agit hoc Romanae avaritiae gurges inexplebilis, qui dum nequit explero, novit resecanda tueri"), y en otro pasaje se extendía en condenar la codicia y malicia curiales (G.H. Pertz, MGH SS 8, pp. 463 y 494). A mediados del siglo XII, Gualterio de Châtillon también comparó la Curia con Escila y Caribdis en su conocida sátira contra la venalidad romana, $c f$. A. Hilka, O. Schumann, B. Bischoff, Carmina Burana, pp. 70-74. Los 10 marcos del soborno equivaldrían a unos 1275 mancusos de 1 '95 g (siendo el marco dos tercios de una libra, en este caso troy).

67 S. Fodale, Comes et legatus.

68 J.P. Migne, $P L$ 151, col. 507-509.

69 A. Hofmeister, MGH SS rer. Germ. 45, p. 315. 
Es interesante observar que la lista de fuentes de la financiación pontificia mencionada en la Garcineida $^{70}$ se corresponde casi exactamente con estos chocantes casos: España (el Arzobispo de Toledo y los reyes de Aragón), Francia (el Arzobispo de Vienne, los obispos de Limoges, Amiens y Beauvais y el Abad de Vendôme), Inglaterra (Herberto de Losinga y Guillermo II) y Apulia (los príncipes normandos), si bien no hemos encontrado ningún caso en Flandes, también mencionado, aunque Urbano mantuvo correspondencia con el conde Roberto ${ }^{71}$.

Estas presuntas corruptelas fueron protagonizadas, en muchos casos, por hombres cuyo constatado afán reformista no se reñía con ocasionales prácticas venales. Cabe considerar que éstos y otros hechos similares debieron transmitir al público una impresión de codicia y corrupción sumamente hipócrita. Más aún en una época de extraordinaria difusión del debate políticoreligioso, con constantes apelaciones a la opinión pública ${ }^{72}$.

La Cátedra de San Pedro, convertida en juguete para las luchas de poder del patriciado romano, arrastraba una pésima fama desde la "pornocracia" del siglo X, revivida e incluso empeorada en el XI. Llegó a haber tres papas simultáneos, todos ellos depuestos en el sínodo de Sutri (1046). Benedicto IX (1032-1044, 1045 y 1047-1048), que vendió su cargo por 1.500 libras de oro, fue infame por sus asesinatos y excesos sexuales, hasta el punto de que su mero recuerdo horrorizaba a gregorianos como Víctor III (1086-1087) o el obispo Bonizo de $\mathrm{Sutri}^{73}$. Hacia 1050, el reformador Pedro Damián escribió su célebre Liber Gomorrhianus, donde se explayaba en los vicios sexuales de un

70 M. Pérez, Garcineida, pp. 258-261.

71 En su edición y traducción críticas -y siguiendo a M.R. Lida, Garcineida, p. 255-, M. Pérez, Garcineida, pp. 217 y 267, considera que la expresión "Apulia sit ubique" ("que Apulia esté en todas partes") carece de sentido literalmente, y la traduce "que todo el mundo tenga sed", estimando esta región como el paradigma de la aridez. Sin embargo, una vez conocido el hecho de que los príncipes normandos fueron el mayor sostén económico y político de Gregorio VII, Víctor III y Urbano II, el doble sentido de la locución parece meridianamente claro: que toda la Cristiandad sostenga al legítimo Papa como lo hace la generosa Apulia. La traducción de R.M. Thomson, Tractatus Garsiae, p. 36, recogida por E. Benito, J.A. Villar, Garcineida, p. 403 ("Let opulence be everywhere", "que haya opulencia por todas partes") es mucho más acertada. En este contexto, tampoco tiene dificultad la siguiente expresión, "diabolus sit pauper", "que el diablo sea pobre" (es decir, que el Antipapa-Anticristo no disponga del nervio de la guerra, las preciadas reliquias de los mártires Albino y Rufino), mal traducida como que "el Diablo no tenga trabajo". C. Codoñer, Reforma gregoriana, p. 465, expresa una idea similar a la nuestra, estimando que la expresión se debe al apoyo apulense al Papa.

72 L. Melve, Inventing the Public Sphere.

73 A. Hofmeister, $M G H S S$ 30-32, p. 1141; E. Dümmler, $M G H L d l$ 1, p. 584. Curiosamente, el comprador, que creía hacer una buena acción con ello, fue el arcipreste Juan de Graciano -Gregorio VI-, cuyo secretario y hombre de confianza fue Hildebrando de Toscana, el futuro Gregorio VII. Sobre Benedicto IX, cf. R.L. Poole, Benedict IX and Gregory VI; K.J. Herrmann, Das Tuskulanerpapsttum. 
clero degradado, lo cual provocó un tremendo escándalo, siendo considerado exagerado incluso por los críticos ${ }^{74}$. Añadiendo más leña al fuego, en 1057, Humberto de Moyenmoutier, cardenal obispo de Silva Cándida, publicó su Adversus simoniacos, que espolearía la reforma gregoriana ${ }^{75}$.

La denuncia de la corrupción eclesiástica estuvo muy extendida a mediados del siglo XII. Aparte de toda la poesía goliárdica, críticas de reformistas como Bernardo de Claraval y literatura antipapal que conservamos, sabemos de una "encuesta" conducida por la propia Roma a tal respecto. Un férreo defensor del Papado, Juan de Salisbury, secretario y confidente de su compatriota Adriano IV (1154-1159), interrogado por éste acerca de qué opinaba el pueblo llano de la Iglesia y de él mismo, le respondió con total sinceridad que, según decían muchos, más que Madre parecía una malvada madrastra ${ }^{76}$ :

Se sientan en ella escribas y fariseos, que ponen trabajos insoportables sobre los hombros de los hombres (...) Señorean sobre el clero (...), amontonan preciosos ajuares, cargan sus mesas con oro y plata, y aún es demasiado poco para su propia avaricia. Arruinan las iglesias, provocan querellas, enemistan a clero y pueblo, carecen de compasión por aquellos afligidos por trabajos y miserias, disfrutan el botín de las iglesias y reputan toda ganancia como piedad. La justicia no es tanto la verdad como el precio pagado. (...) Incluso el propio pontífice romano es gravoso y casi intolerable para todos; $y$ además dicen que, mientras las iglesias que construyó la devoción de sus padres están en ruinas y colapso, e incluso los altares sin culto, construye palacios y él mismo se pasea no ya ataviado de púrpura, sino de oro. Los palacios de los sacerdotes relucen, y en sus manos yace harapienta la Iglesia de Cristo. Arrancan el botín de las provincias como si quisieran reponer los tesoros de Creso.

Unos juicios que, a finales del XI, debieron verse favorecidos por los partidarios de 'Clemente III' 77 , así como por las críticas del ala más intransigente de los reformistas, contraria a la contemporización con simoníacos y laicos, característica de la política de Urbano II. En palabras de la Garcineida, que desde luego coincide con los casos anteriormente expuestos ${ }^{78}$ :

74 J.P. Migne, PL 145, col. 159-190; P.J. Payer, Book of Gomorrah.

75 E. Dümmler, $M G H L d l$ 1, pp. 95-252.

76 C.C.J. Webb, Ioannis Saresberiensis Policratici, vol. II, pp. 67-68, cf. M. González, Juan de Salisbury.

77 Por ejemplo, K. Francke, MGH Ldl 2, pp. 408-422, o los casi coetáneos Carmina in simoniam et romanorum avaritiam, en H. Böhmer, MGH Ldl 3, pp. 697-710, algunos dedicados al propio Antipapa. Cf. M. Pérez, Garcineida, pp. 47-48.

78 M. Pérez, Garcineida, pp. 235-241. 
¡Oh, cuán preciados mártires Albino y Rufino (...)! Quienes poseen sus reliquias, al instante se convierten de pecadores en justos, de terrenales en celestiales, de criminales en inocentes. Hemos visto venir ante el Papa a prelados simoníacos, sacrílegos y dilapiladores de sus iglesias, los cuales, purificados con la bendición apostólica gracias a las reliquias de los susodichos mártires, han vuelto a su patria libres de cualquier inculpación (...) Venid, venid, simoníacos, arzobispos, obispos, archidiáconos, abades, deanes y también priores, ofreced al pontífice romano los dos mártires por medio de los cuales está abierta la entrada a la Iglesia romana.

Contamos, además, con otra acerba sátira casi coetánea a la Garcineida, escrita en verso hacia 1096, que tronaba contra los oprobios de la Curia Romana y las decisiones del concilio de Clermont: De filiis presbyterorum, atribuida a Serlón, canónigo de Bayeux (c. 1050-1113 ó 1122) (99. $^{79}$

Para el momento de su muerte, y aunque el antipapa 'Clemente' le sobrevivió, Urbano II, antaño papa desposeído y a la fuga, había logrado ser reconocido por la mayoría de la Cristiandad, aunque su dominio sobre Roma aún fuera harto precario. Visto desde fuera, pudiera parecer lo logró apartándose del camino de la pureza.

\section{5. ¿AUTORÍA GERMÁNICA?}

Siguiendo a Pflugk-Harting, Maurilio Pérez defiende que el autor de la Garcineida fue un teutón partidario del Emperador y el Antipapa, situándolo en el contexto de la Querella de las Investiduras. En apoyo de esta idea incide en el origen alemán del códice A (que ya hemos rechazado) y la peculiar ordenación de las palabras, que le resulta germánica $^{80}$, pero no deja de ser un argumento cuestionable y rebuscado, que el propio autor prefiere dejar en suspenso debido a la falta de estudios a tal respecto.

El profesor Serafín Bodelón hace una crítica de sus planteamientos que vale la pena reproducir íntegra ${ }^{81}$ :

pese al intento de M. Pérez, que ve allí las guerras entre el Sacro Imperio Romano Germánico y el Papado (...), en verdad, tales guerras no aparecen por ninguna parte. Pasa M. Pérez revista al papado de Gregorio VII (...); cita la excomunión de Enrique IV,

79 T. Wright, Anglo-Latin Poets, vol. II, pp 208-212; H. Böhmer, MGH Ldl 3, pp. 579-583;

H. Böhmer, Der sogenannte Serlo von Bayeux.

${ }^{80}$ M. Pérez, Garcineida, pp. 91 y 150-153.

81 S. Bodelón, Maurilio Pérez, p. 157. 
quien aparece en la portada exterior del libro, como si hubiera tenido algo que ver con la Garcineida. Y el ávido lector comienza a leer devorando páginas ansiosamente, pero el tal Enrique IV no aparece por ninguna parte, tampoco aparece Alemania y las únicas guerras que allí se pintan son las bélicas contiendas degustativas de Urbano II contra las variadas clases de pescados, barbos, rodaballos, salmones, lampreas y otros manjares, mezclados con sabrosos y exquisitos vinos, ya se tratara de un Másico o bien de un Falerno. Y no existen en la obra referencias a Alemania, mientras sí existen, y muchas, a España y más concretamente a Toledo. Tanto si el lector comenzó leyendo la pesada introducción, como si se inició deleitándose con el sabroso texto paródico de esta obra tan burlesca, el lector siente que le han tomado el pelo, al situar esta obra como escrita en Alemania, por un autor anónimo teutón y describiendo hechos relativos a Alemania. Nada de esto se deduce del texto, ni allí tales cosas se contienen en mi humilde opinión.

Coincidimos con este juicio. Por supuesto que la Garcineida hace alusiones a la política coetánea; pero ésta no es el centro ni el motivo de la sátira, de igual modo que el Cantar de mío Cid no trata sobre la política exterior de Alfonso VI.

Se trata de una obra original que no se parece a ninguna otra de las producidas por la Querella de las Investiduras, aun cuando se trata de un corpus literario de considerable volumen. No contiene disquisiciones sobre la validez de las ordenaciones simoníacas, ni elaborados argumentos, ni citas con las que apuntalar su tesis. A pesar de su erudición, carece de enjundia doctrinal, motivo por el cual Lida de Malkiel la vinculaba con el goliardismo. En acertadas palabras de Thompson, se trata de la más temprana, elaborada y quizá divertida de las sátiras antipapales que proliferaron en Europa occidental durante el siglo XII ${ }^{82}$ :

Resulta impensable que un pro-imperial se refiriera siempre a Urbano como Pontífice Romano. A todas luces, el autor de la Garcineida sentía tan poco aprecio por los imperialistas como por la Curia Romana. Tanto el Antipapa como el Emperador son injuriados en las escasísimas ocasiones en que se les menciona. Guiberto de Rávena (al que no llama 'Clemente III') es calificado de hereje y descrito como ávido de sangre romana; el emperador Enrique amenazaba con matar al Papa por la espalda (es decir, de forma ruin y traicionera), y ambos son llamados tiranos ${ }^{83}$. Desde luego parece excesivo incluso si creemos que se pretendía caricaturizar las posturas de Urbano y los

82 R.M. Thomson, Tractatus Garsiae, p. 5. Sobre la literatura polémica generada por las luchas entre gregorianos e imperiales, $c f$. I.S. Robinson, Authority and Resistance.

83 M. Pérez, Garcineida, pp. 250-253, 258-259 y 262-263. 
suyos a este respecto. Si los defensores del Emperador y el Antipapa les dedicaban tales denuestos, entonces no necesitaban enemigos.

El profesor Maurilio Pérez, propone como un posible móvil del autor que los rivales de Urbano II pensaban que Bernardo de Toledo fácilmente podría ser el siguiente papa. Sin embargo, se contradice unas páginas más adelante al defender una fecha de redacción entre 1110 y 1118, es decir, después de su muerte y durante el pontificado de Pascual II ${ }^{84}$, cuando la estrella de Bernardo estaba ya en franco declive ${ }^{85}$. Coincidimos con Serafín Bodelón cuando firma que habría sido de muy mal gusto hablar de un muerto tan mal como se hace en esta obra, situando la redacción antes del fallecimiento de Urbano $(1099)^{86}$. Parece evidente el interés en condenar a un papa vivo y a su curia.

Pero incluso si suponemos que Bernardo fuera considerado como un posible sucesor de Urbano II, y no de Pascual, tal argumento es por completo espurio. Cierto canon antiguo había establecido que sólo los cardenales podían ser elegidos papas ${ }^{87}$. Según la bula de Nicolás II In nomine Domini (1059), el Papa debía ser elegido entre el clero romano, a menos que no se encontrara en el mismo un candidato apto ${ }^{88}$. A partir de Alejandro II (1061-73), que en apariencia no fue cardenal, la norma fue seguida al pie de la letra: todos los papas de finales del siglo XI y del siglo XII -es decir, antes, durante y después de la vida eclesiástica de Bernardo de Sauvetat-fueron cardenales de la Curia Romana ${ }^{89}$. Hasta los antipapas que sucedieron a 'Clemente III' se ciñeron a esta norma canónica: Teodorico (1100-1101) y Adalberto (1101-1102), anticardenales obispos de Albano y Santa Rufina, respectivamente.

En cambio, el Arzobispo de Toledo no fue cardenal ni miembro de la Curia. Lo cual imposibilitaba su elección al Papado y echa por tierra el presunto móvil por el cual ese inexistente autor alemán y pro-imperial habría elegido a Bernardo como eje de su obra.

\section{6. ¿REALIDAD O FICCIÓN?}

Se supone ficticia la recepción caricaturizada en la obra que nos ocupa. Sin embargo, y además de cuánto hemos expuesto sobre Urbano II, la fidelidad histórica de la misma es notabilísima. Contiene detalles tan oscuros

84 Ibidem, pp. 88-89 y 93-97.

85 Cf. J.F. Rivera, El arzobispo de Toledo Don Bernardo de Cluny, pp. 61-81.

86 S. Bodelón, Maurilio Pérez, p. 155.

87 Can. Oportebat et seq. dist. 79.

88 G.H. Pertz, MGH Leges I-2, pp. 176-180.

89 Cf. R. Hüls, Kardinäle; I.S. Robinson, Papacy, pp. 33-120. 
como una referencia casual a la toma del Castel Sant'Angelo, conocida únicamente por noticias escuetas en un par de crónicas ${ }^{90}$.

Es real el arzobispo de Toledo, escondido bajo el pseudónimo de Grimoardo $^{91}$, que además es descrito con insólita minuciosidad ${ }^{92}$. Su viaje a Roma en la primavera de 1099 fue real. Quizá no para comprar la legacía para la Narbonense, que ya desempeñaba desde 1093. Igual sí para renovarla. Desde luego, el 4 de mayo de 1099 el Papa le confirmó sus privilegios y le entregó como sufragáneas las sedes del Oviedo, León y Palencia, además de todas las dependientes antaño de Toledo, refiriéndose a él como personam propensiori gratia in nostra manu tenendam ${ }^{93}$. La bula fue declarada subrepticia en 1104. Por tanto, no hay motivo para pensar que no parodiara la verdadera recepción del arzobispo toledano.

También son reales el papa Urbano II y todos los prelados que aparecen en la obra: Teuzo (Teucro), cardenal presbítero de San Juan y San Pablo94; Gregorio, benedictino, obispo de Pavía y cardenal diácono de Santa Lucía in Septisolio ${ }^{95}$; el Pisano, cuya identificación con Pedro de Pisa -que aún no era cardenal- cuestiona Maurilio Pérez con buen criterio ${ }^{96}$; Rangerio, benedictino, obispo de Lucca, cardenal presbítero de Santa Susana ${ }^{97}$; Odón

90 R.M. Thomson, Tractatus Garsiae, pp. 86-87.

91 M. Pérez, Garcineida, pp. 90-91, le atribuye un origen germánico, lo cual es cierto. Más concretamente, franco. Cabe reseñar que "Grimo-ardo", es decir, "que arde de grima", puede no ser sólo una sátira de "Bern-ardo", sino tratarse de un apellido occitano ya existente en la época, quizá el del Arzobispo de Toledo, como sugiere C. Codoñer, Reforma gregoriana, p. 468. Apoyando su teoría, el papa Urbano V (1362-1370) se llamaba Guillaume Grimoard, y nació en Grizac, a unos 300 km de La Sauvetat-sur-Lède, patria de Bernardo; hasta hubo toda una casa condal de Grimoard. Lo cual, desde luego, nos aleja de Alemania y la Querella de las Investiduras.

92 M. Pérez, Garcineida, pp. 274-275 y 286-287: "seboso, cebado, suntuoso, redondo, pesado, gravoso, rudo, ciclópeo, de cuerpo gigantesco, pecho amplio, vientre inmenso, anchas espaldas, entrecejo grande, frente contraída, rostro terrorífico, aspecto grave, cabellera hirsuta, pescuezo gordísimo (...) no entra por las puertas, es un ladrón y un bandido". Contrasta con la descripción de la primera Crónica Anónima de Sahagún: "honrrado varón (...) de toda prudençia e discreçión e de muy alta religión, e aún según la dignidad del mundo no era de poca nobleça" (A. Ubieto Arteta, Crónicas, p. 14).

93 J.F. Rivera, El arzobispo de Toledo Don Bernardo de Cluny, pp. 45-46 y 54.

94 R. Hüls, Kardinäle, p. 218, que lo diferencia de un anticardenal homónimo partidario de 'Clemente III' y legado suyo en Hungría. C. Codoñer, Reforma gregoriana, p. 468, cree que en realidad "Teucro" se refiere al obispo de Troia (Apulia), Gerardo, pero éste no fue cardenal.

95 R. Hüls, Kardinäle, p. 237.

96 M. Pérez, Garcineida, pp. 95-96; C. Codoñer, Reforma gregoriana, p. 469, defiende su identificación con Pedro de Pisa, estimando clara la tendencia del autor a citar a los prelados por sus sedes. Creemos que "Pisanus" se refiriera posiblemente a Lamberto Scannabecchi, benedictino, cardenal presbítero de Santa Prassede y futuro Honorio II, natural de Imola, que estudió en Pisa, $c f$. R. Hüls, Kardinäle, pp. 106-107.

97 R. Hüls, Kardinäle, pp. 207-209. 
de Châtillon, benedictino, cardenal obispo de Ostia y sobrino de Urbano II ${ }^{98}$; Bruno, cardenal obispo de Segni ${ }^{99}$; Alberto, benedictino, cardenal presbítero de Santa Sabina ${ }^{100}$; y Juan de Gaeta, benedictino, cardenal diácono de María in Cosmedin y canciller, futuro Gelasio II.

El único condenado a la inexistencia es, al parecer, García ${ }^{101}$.

\section{7. ¿AUTORÍA HISPÁNICA?}

Como hacía notar Rodney Thomson, tan sólo un español hubiera considerado la visita de Bernardo de Toledo a Roma lo suficientemente importante como para convertirla en base argumental y eje de su sátira ${ }^{102}$ : Si todo fuera ficción, el personaje sería superfluo; podría haber sido cualquier otro. Que la obra no se prodigue en digresiones sobre la situación de la Iglesia en España no prueba nada en contra de la autoría española. Como mucho, que se atribuía el origen de esos problemas a la corrupción pontificia, más que a la originalidad de las prácticas del Arzobispo de Toledo. La Iglesia hispana fue la que más atención y legacías recibió en el último tercio del siglo $\mathrm{XI}^{103}$ y la Garcineida consiste en la iniciación de Bernardo, hasta que la Curia le reconoce como un verdadero romano.

Serafín Bodelón indica con gran sagacidad que un teutón habría hablado de un viaje de Colonia a Roma, o de Worms a Rávena, o tal vez de Maguncia a Bolonia, pero nunca habría perfilado un viaje de Toledo a Roma ${ }^{104}$.

En cambio, un cluniacense afincado en España o un clérigo local asociado a los ambientes reformistas parecen los candidatos más plausibles para la autoría.

Los lazos entre Cluny y España son evidentes. Mientras que Aragón se vinculó personalmente con la Sede romana, los reyes leoneses prefirieron aliarse con la nobleza borgoñona y el influyente monasterio como el menor de los dos males, buscando mantener su independencia frente a las pretensiones pontificias de supremacía universal. No sólo los cluniacenses se infiltraron en todos los niveles de la jerarquía eclesial hispana, sino que la abadía pasó a depender por completo del dinero español. Ya en 1062 Fernando I de León se

98 Ibidem, pp. 103-105.

99 Ibidem, pp. 129-130.

100 Ibidem, p. 203.

101 En palabras de S. Bodelón, Maurilio Pérez, p. 158.

102 R.M. Thomson, Tractatus Garsiae, p. 5.

103 R. Fletcher, Las iglesias del reino de León.

104 S. Bodelón, Maurilio Pérez, p. 158. 
comprometió a pagar un censo anual de 1.000 mancusos. En 1077, Alfonso VI desembolsó 10.000, en concepto de atrasos, y prometió doblar el censo de su padre, una suma que excedía -con mucho- a todas las rentas ordinarias que Cluny obtenía de todas sus propiedades y derechos, convirtiéndose en la principal fuente de financiación de la abadía. Estos ingresos extraordinarios permitieron a Hugo el Grande emprender la construcción de la tercera iglesia de la casa monástica, el mayor templo de la Cristiandad, con 187 metros de longitud. Así, un coetáneo, Beroldo de Constanza, afirmaba que Alfonso VI había financiado la nueva iglesia abacial. Es decir, el grueso del dinero con el que Cluny sostenía a Urbano II procedía de España. No es de extrañar que hubiera alarmas cada vez que el Arzobispo de Toledo se acercaba a la Curia, no fuera a ser que su intermediación desapareciera, quedando al margen. El declive de la orden comenzó cuando el censo alfonsino dejó de pagarse, en $1111^{105}$.

Además, el rey leonés donó a Cluny cuatro importantes monasterios reales: San Isidoro de Dueñas (1073), San Salvador de Palat del Rey (1076), Santiago de Astudillo (1077) y San Juan de Hérmedes de Cerrato (1077), todos ellos convertidos en prioratos, a los que se sumaron Santa María de Nájera (1079) y Santa Columba de Burgos (1081) ${ }^{106}$. Los grandes abades cluniacenses consideraron oportuno viajar a sus posesiones de España y entrevistarse con los reyes leoneses: Hugo el Grande en 1090, Poncio en 1113 y Pedro el Venerable en $1142^{107}$.

A la contra que su soberano, Bernardo de Sauvetat logró que la abadía de Sahagún se desvinculara de Cluny y pasara a depender directamente de Roma $(1083)^{108}$. No donó ni un solo monasterio ni se preocupó de extender la influencia de su orden en España. Tan sólo subordinó San Servando de Toledo a la abadía de San Víctor de Marsella, en 1088. Casualmente, el abad de San Víctor era Ricardo de Millau, legado pontificio en España. Ese mismo año presidió el Concilio de Husillos, que, entre otros asuntos, estableció los límites de la disputada diócesis de Osma, a pesar de haberse opuesto a la elección de Urbano II y hallarse excomulgado. Bernardo también instauró los usos cluniacenses en Santa María de Batres, pero lo mantuvo sujeto a su autoridad episcopal, dejando clara su opinión sobre la libertad monástica ${ }^{109}$. Ello a pesar

105 Sobre las finanzas cluniacenses, $c f$. R. Alcocer, Relaciones económicas; G. Duby, Economie domaniale. Sobre las relaciones de la monarquía leonesa con Cluny, cf. C.J. Bishko, Liturgical Intercession at Cluny; C.J. Bishko, Fernando I; J.M. Mínguez, Alfonso VI, pp. 211228; H.S. Martínez, Vasallaje castellano-leonés a Cluny; C.M. Reglero, Cluny en España, pp. $145-152$.

106 C.M. Reglero, Cluny en España, pp. 152-155.

107 C.J. Bishko, Peter the Venerable's Journey; C.J. Bishko, The Spanish Journey.

108 J.F. Rivera, El arzobispo de Toledo Don Bernardo de Cluny, pp. 13-17.

109 C.J. Bishko, The Abbey. 
de que Hugo el Grande, en la carta que le dirigió en 1087, le indicaba que se había esforzado mucho para que obtuviera su sede y esperaba que recordara su obediencia debida a su antigua casa y a su padre espiritual ${ }^{110}$. En efecto, no fue hasta 1088 que Urbano II, presionado por Hugo, ratificó su elección y le constituyó primado, enviándole el palio ${ }^{111}$.

Sin embargo, una vez elevado al arzobispado toledano, Bernardo se entregó a incrementar su poder personal, dedicándose casi en exclusiva a engrandecer su sede por todos los medios posibles: obtuvo la legacía papal; impidió la restauración del obispado de Alcalá; retrasó el restablecimiento de las diócesis de Osma y Segovia, a fin de seguir administrando sus territorios y embolsándose sus rentas; convirtió Oviedo, León y Zamora en sufragáneas; y mantuvo luchas de poder con otros prelados poco escrupulosos, como Diego Gelmírez, cuya buena estrella ascendió a la par que decaía la suya propia, motivo por el cual Bernardo tenía sus buenas razones para sobornar a la Curia Romana en defensa de sus privilegios ${ }^{112}$. Sabemos por Jiménez de Rada que este turbulento personaje dejó la carrera eclesial para dedicarse al oficio de las armas, integrándose a la vida monástica en Saint-Orens d'Auch como resultado de un voto tras una enfermedad ${ }^{113}$.

Cabe pensar que el nombre 'García' fuera ficticio, para eludir posibles represalias. Pero nada más. La hostilidad de los toledanos hacia su arzobispo fue pública y notoria: con ocasión de su asistencia al Concilio de Clermont, en 1095 , se rebelaron, eligieron un nuevo prelado y expulsaron a sus leales ${ }^{114}$.

Pero más que un mozárabe descontento con la imposición del rito romano, pensamos que el autor de la Garcineida debió ser de uno de sus cluniacenses o un filocluniacense perteneciente al alto clero hispano, ya fuera nativo o francés. Debemos suponer que existió cierto descontento ante unos presuntos reformistas y enemigos de la simonía que, a la postre, resultaban no serlo tanto. Podrían haber parecido, más bien, unos hipócritas interesados únicamente en la alta política y el expolio de sus diócesis. Resultaría chocante que Bernardo se comportara de forma tan reprobable, y no sería raro asociar esa corrupción con Roma, que le puso al frente de su sede, toleraba sus desmanes y le confirmaba un privilegio tras otro. El Arzobispo de Toledo se hallaba ausente mientras la antigua capital visigoda era asediada dos veces por los almorávides (1099 y 1100).

110 M. Férotin, Lettre inédite; idem, Complément; J.F. Rivera, El arzobispo de Toledo Don Bernardo de Cluny, pp. 67-69.

111 J.P. Migne, PL 151, col. 288-91.

112 J.F. Rivera, El arzobispo de Toledo Don Bernardo de Cluny, pp. 29-64.

113 Ibidem, p. 11.

114 Ibidem, pp. 50-51. 
España poseía unos ambientes intelectuales perfectamente capaces de producir una obra como la que nos ocupa, que hace gala de un espectacular despliegue de cultura clásica, y claras influencias de Terencio, Horacio, Plauto, Ovidio, Juvenal, César, Salustio y Persio ${ }^{115}$. Así, dentro de la clerecía áulica hispánica, el autor de la Historia Silense, muestra un minucioso conocimiento de Virgilio, Horacio, Ovidio, Lucano y Salustio, así como nula simpatía por los francos. Pérez de Urbel creyó posible su atribución a Alón, obispo de Astorga (1122-1131), a quien también se ha adjudicado el Cronicón Compostelano y parte del Poema de la Conquista de Toledo. Alón formó parte del séquito de Bernardo de Toledo, en su condición de grammaticus del rey Alfonso, como mínimo en $1101^{116}$.

Entre el clero hispano contamos con un candidato ideal para la autoría de la Garcineida. Se llamaba García, al igual que el narrador de esta obra, llegó casualmente (forte) a Roma con Bernardo de Toledo ${ }^{117}$ y tenía motivos para proclamarse siervo del Arzobispo de Toledo, aunque no nos conste que fuera hombre de gran cultura (el García literario se declaraba poeta) ${ }^{118}$.

Nos referimos a García Aznárez, obispo de Burgos (1097-1114), que mantenía un contencioso con Bernardo por los límites de la diócesis de Osma. No era canónigo de la Iglesia de Toledo ni siervo de su Arzobispo, pero podía considerarse amargamente como tal, a pesar de que su sede estaba directamente sometida a Roma. Quizá le asombrara que la Curia aumentara los privilegios de Bernardo, quien seguiría usufructuando los territorios usurpados por un plazo de tres años, dentro del cual había de nombrar un obispo para Osma. Sede que acabaría siendo ocupada -naturalmente- por un miembro de su séquito, el también cluniacense Pedro de Bourges ${ }^{119}$.

García de Burgos, desde luego, podía dirigirse al Papa -como ocurre con el personaje de García - y permitirse tronar contra el Arzobispo y contra Roma sin mucho temor a posibles represalias, pues era un hombre poderoso. Sabemos que no tuvo buenas relaciones con Bernardo, y fue el encargado de consagrar a su mayor enemigo, Diego Gelmírez (1101). A instancia suya, el papa Pascual II revisó los límites de la archidiócesis toledana y dedicó una

115 M. Pérez, Garcineida, pp. 99-109.

116 J. Pérez, A. González, Historia Silense, pp. 54-60 y 68-87. Otro posible autor de la Silense es el obispo Pelayo de León (1065-1087), si bien la cronología de este prelado parece demasiado temprana (M. Carriedo, Pelayo Tedóniz). A. Isla, La historiografía, ha insistido en la vinculación de la obra a San Isidoro de León.

117 M. Pérez, Garcineida, pp. 230-231.

118 Ibidem, pp. 274-275.

119 L. Serrano, Obispado de Burgos, pp. 358-363; B. Bartolomé, Historia de las diócesis, pp. 46-55; García obtuvo de Urbano el reconocimiento de su dependencia directa de Roma y los límites de su diócesis (4 de mayo de 1099). 
durísima carta a su Arzobispo, reprendiéndole por sus ausencias, total descuido de sus deberes pastorales y empeño exclusivo en engrandecer su sede (sic), excluyendo a Osma de su jurisdicción y suspendiendo su legacía (1108). A lo cual Bernardo reaccionó ignorándole y ocupando militarmente los territorios de la diócesis oxomense reclamados por Burgos. Además, Pascual II dejó exentos los obispados de Oviedo y León. Su posición se iría deteriorando mientras Gelmírez acumulaba más y más poder y se sucedían las luchas con Alfonso el Batallador (cuyo enlace con Urraca fue muy probablemente oficiado por el propio García Aznárez), el cual expulsó brevemente tanto a García como a Bernardo de sus respectivas sedes. Cuando el primero murió, el arzobispo toledano se aseguró de que fuera sucedido por un candidato de su elección ${ }^{120}$.

\section{8. ¿AUTORÍA FRANCESA?}

No habiendo pruebas fehacientes de la autoría de García Aznárez, hay que considerar otros posibles candidatos entre los clérigos francos llegados con el propio Bernardo de Sauvetat, a fin de reemplazar al clero levantisco de su archidiócesis por gente más manejable. Esta élite intelectual cluniacense incorporada, en un primer momento, al cabildo toledano (el cual siguió incluyendo hispanos), iría ascendiendo hasta ocupar diversas sedes ${ }^{121}$.

Contamos, entre ellos, a Mauricio Burdin, (arcediano de Toledo, obispo de Coimbra, arzobispo de Braga y antipapa como 'Gregorio VIII') ${ }^{122}$. Gerardo de Moissac (chantre de Toledo y arzobispo de Braga), Pedro de Bourges (obispo de Osma), Dalmacio (obispo de Santiago) ${ }^{123}$, Pedro de Agén (arcediano de Toledo, obispo de Segovia), su hermano Bernardo de Agén (primicerio de Toledo, obispo de Sigüenza, capellán de Alfonso VII y arzobispo de Santiago), su sobrino Pedro de Agén (obispo de Palencia), Jerónimo de Périgord (obispo de Valencia, Zamora, Salamanca y Ávila, posible autor de la Historia Roderici) ${ }^{124}$, y, por supuesto, a Raimundo de Sauvetat (paisano de

120 L. Serrano, Obispado de Burgos, pp. 363-386; J.F. Rivera, El arzobispo de Toledo Don Bernardo de Cluny, pp. 60-98; A. Gambra, Alfonso VI.

121 M. Defourneaux, Les français, pp. 35-37; J.F. Rivera, La Iglesia de Toledo, v. II, pp. 22-25.

122 C. Erdmann, Mauricio Burdino; J.F. Rivera, El arzobispo de Toledo Don Bernardo de Cluny, pp. 76-84.

123 A. López, Historia de la Santa, vol. III, pp. 181-190; J.F. Rivera, El arzobispo de Toledo Don Bernardo de Cluny, pp. 244-246.

124 J.L. Moralejo, Literatura hispano-latina, p. 65; C. Lacombe, Jerónimo de Perigueux. Sobre los problemas de esa obra y posibles cronologías más tardías, $c f$. A. Montaner Frutos, A. Escobar Chico, Carmen Campidoctoris, pp. 77-87 y 119. 
Bernardo, obispo de Osma, arzobispo de Toledo, Canciller de Castilla y fundador de la Escuela de Traductores) ${ }^{125}$.

Sabemos de la presencia de escribas cluniacenses en la España coetánea, como un tal Arriolfus ${ }^{126}$. A los que podríamos sumar otros dos franceses, el arcediano Hugo de Portugal (luego obispo de Oporto) y el presbítero Gerardo de Beauvais, dos de los autores de la Historia Compostelana, aunque no fueran cluniacenses ${ }^{127}$.

Algún miembro del amplio séquito del Arzobispo pudo tener un bajo concepto del mismo, aliviando su conciencia al escribir o transmitir la sátira que nos ocupa.

Con su gran poder, vasta cultura, reconocido patrocinio escriptorio, conocimiento personal de Bernardo y facilidad para divulgar la obra en el siglo XII, el cluniacense Raimundo de Sauvetat (c. 1080-1152) sería el candidato más plausible de este grupo, pero en apariencia fue totalmente leal a su predecesor.

Es también relevante el caso de Aymerico Picaud, autor del celebérrimo liber Beati Iacobi, cuya guía de peregrinaje acaba con un explicit señalando que está siendo escrita (es decir, copiada y distribuida) en diversos lugares: Roma, Jerusalén, Galia, Italia, Alemania, Frisia y, sobre todo, en Cluny ${ }^{128}$.

Lo cual demuestra los vínculos españoles con el scriptorium de su compañero de hábito, el también pontevino Ricardo el Pictaviense, en cuya obra se halla inserta una de las cuatro copias de la Garcineida.

En apoyo de esta teoría, Carmen Codoñer también ha señalado la existencia de una copia de crónica del Pictaviense en un manuscrito hispano del siglo XIII, cuyo origen parece haber sido Toledo, además de señalar que las cartas de Ivo de Chartres en el códice A son reseñables por la proximidad de esa ciudad a Poitou ${ }^{129}$. Cabe añadir que Cerebruno de Poitiers, obispo de Toledo entre 1166 y 1180, ya era arcediano desde 1143, y su hermano Pictavino canónigo en $1149^{130}$, estrechando aún más los vínculos entre la Garcinei$d a$ y el Pictaviense. Ya se ha indicado que Pedro el Venerable visitó España en 1142; a su secretario, Pedro -de nuevo un natural de Poitiers-, se le han

125 A. González, El arzobispo Don Raimundo de Toledo.

126 A. Gambra, Alfonso VI, vol. I, p. 170.

127 L. Sala, Los autores de la "Historia Compostelana"; E. Falque, Los autores de la "Historia Compostelana".

128 J. Vielliard, Guide du pelerin, p. 124; C. Romero, J. Gerra, J. Filgueira, Libro de la Peregrinación, pp. 23 y 54; M.C. Díaz, "Liber Sancti Iacobi", considera falso el pretendido vínculo del autor con el papa Calixto II.

129 C. Codoñer, Reforma gregoriana, p. 461.

130 J.F. Rivera, La Iglesia de Toledo, vol. I, pp. 199-200 y 261-266. 
atribuido la Chronica Adefonsi Imperatoris y el Poema de Almería ${ }^{131}$. Combatiendo esta teoría, el otro posible autor de los mismos es Arnaldo, obispo de Astorga (1144-1153), cuyo nombre es francés y quizá fuera también cluniacense $^{132}$.

Parece natural que la obra se difundiera en ambientes cluniacenses a mediados del XII. La Orden parecía adaptarse con dificultad a los nuevos tiempos ${ }^{133}$. Un coetáneo, Bernardo, insistía en la venalidad del clero y la Curia en su De contemptu mundi. En aquellos momentos Roma se hallaba en estado de anarquía, mientras los enemigos de Cluny, encabezados por una escisión de la propia Orden, el Císter, afianzaban su poder y denunciaban la mundanidad tanto de Cluny como del Papado, pero no dejaban de aproximarse a este último. Inocencio II (1130-1143) fue elegido de forma anticanónica, en oposición a un antipapa cluniacense de la poderosa familia Pierleoni, 'Anacleto II' (hijo de Petrus Leonis, el gran apoyo de Urbano II), aunque Cluny se mantuviera leal a Inocencio. Si logró ser reconocido y recuperar Roma (Segundo Concilio de Letrán, 1139) fue gracias al apoyo de Bernardo de Claraval; en 1132 abolió los derechos pagados por los cistercienses a Cluny, y en 1141 condenó a su mayor antagonista intelectual, Pedro Abelardo, que había pasado sus últimos años acogido por Pedro el Venerable en Cluny. Lucio II (1144-1145) fue expulsado de Roma por Giordano Pierleoni (hermano de 'Anacleto II'), muriendo por las heridas recibidas en combate al tratar de reconquistar la Urbe. Fue sucedido por un cisterciense, Eugenio III (1145-1153), que se dejaba guiar por su antiguo maestro claravalense, quien le dedicó todo un tratado con instrucciones precisas (De consideratione $)^{134}$.

\section{CONCLUSIONES}

En primer lugar, queda demostrado que la corrupción de la Curia durante el pontificado de Urbano II, tema central de la Garcineida, no era algo ficticio. Se correspondía con una percepción bastante extendida-fuera o no acertada-, reflejada no sólo en otras fuentes coetáneas opuestas al Papado, sino en la propia documentación pontificia. Por tanto, aún siendo una sátira, debemos considerarla histórica, y no meramente literaria.

En segundo, queda también clara la inconsistencia de los argumentos esgrimidos por el profesor Pérez González en defensa de una autoría germáni-

131 A. Ferrari, El cluniacense.

132 A. Quintana Prieto, Sampiro, Alón y Arnaldo.

133 J. Leclercq, The Monastic Crisis.

134 Cf. I.S. Robinson, The Papacy, pp. 14-15, 23-24, 207, 212, 216-220, 245-247 y 266-267. 
ca de la Garcineida y apuntados los hechos que hacen plausible la hispánica, ya se trate de un clérigo local o un francés del círculo del Arzobispo de Toledo.

Por último, se establece que la obra fue copiada y difundida por cluniacenses a mediados del siglo XII, en un momento de decadencia de la Orden, deterioro de las relaciones con el Papado y crisis interna por la aparición de críticos reformistas como Bernardo de Claraval.

\section{BIBLIOGRAFÍA CITADA}

Adcock, Fleur (ed.), Hugh Primas and the Archpoet, Cambridge, Cambridge University Press, 1994.

Alcocer, Rafael, Relaciones económicas entre los Reyes de España y Cluni, "Revista histórica: investigaciones, bibliografía, metodología y enseñanza de la historia" 1 (1918), pp. 161-168 y 201-209.

Atherton, Ian (ed.), Norwich Cathedral: Church, City, and Diocese, 10961996, Londres, Hambledon, 1996.

Barlow, Frank, William Rufus, Los Angeles, University of California Press, 1983.

Barreiro Somoza, José, Ideología y conflicto de clases (siglos XI-XIII), Santiago de Compostela, Pico Sacro, 1977.

Bartolomé Martínez, Bernabé (ed.), Historia de las diócesis españolas 20 Iglesias de Burgos, Osma-Soria y Santander, Madrid, Biblioteca de Autores Cristianos, 2004.

Benito Ruano, Eloy; Villar Vidal, José Antonio, La Garcineida, "Medievalismo" 7 (1997), pp. 365-413.

Becker, Alfons, Papst Urban II (1088-1099), Stuttgart, Hiersemann, 1964-1968.

Berger, Élie, Notice sur divers manuscrits de la Bibliothèque Vaticane: Richard le Poitevin, moine de Cluny, historien et poète, Toulouse, Ernest Thorin, 1879.

Bishko, Charles Julian, Peter the Venerable's Journey to Spain, "Studia Anselmiana" 40 (1956), pp. 163-175.

Bishko, Charles Julian, The Spanish Journey of Abbot Ponce of Cluny, "Ricerche di Storia Religiosa" 1 (1957), pp. 311-319.

Bishko, Charles Julian, Liturgical Intercession at Cluny for the King-Emperors of Spain, "Studia monástica" 3 (1961), pp. 53-76.

Bishko, Charles Julian, Fernando I y los orígenes de la alianza castellanoleonesa con Cluny, "Cuadernos de Historia de España" 47-48 (1968), pp. 31-135 y 49-50 (1969), pp. 50-116.

Bishko, Charles Julian, The Abbey of Santa Maria de Batres and the Cluniac Presence at Toledo from Alfonso VI to Alfonso VII, en Estudios so- 
bre Alfonso VI y la reconquista de Toledo. Actas del II Congreso Internacional de Estudios Mozárabes (Toledo, 20-26 Mayo 1985), Toledo, Instituto de Estudios Visigótico-Mozárabes, 1988, vol. I, pp. 187-218.

Bodelón García, Serafín, Literatura latina de la Edad Media en España, Tres Cantos, Akal, 1989.

Bodelón García, Serafín, Maurilio Pérez, La Garcineida. Estudio y edición crítica con traducción, "Tiempo y sociedad” 6 (2011-2012), pp. 154-160.

Böhmer, Heinrich, Der sogenannte Serlo von Bayeux und die ihm zugeschriebenen Gedichte, "Neues Archiv der Gesellschaft für ältere deutsche Geschichtskunde" 22 (1897), pp. 701-738.

Böhmer, Heinrich (ed.), MGH Libelli de lite 3, Hannover, Hahn, 1897.

Cairns, Francis, The Addition to the Chronica of Richard of Poitiers, "Mittellateinisches Jahrbuch” 19 (1984), pp. 159-161.

Carriedo Tejedo, Manuel, Pelayo Tedóniz, obispo de León (1065-1085 y 1086 1087): ¿Autor de la 'Historia Silense?, en Fernández Catón, José María (coord.), Monarquía y sociedad en el reino de León: de Alfonso III a Alfonso VII, León, Centro de Estudios e Investigación San Isidoro, 2007, vol. II, pp. 395-456.

Charlo Brea, Luis, Maurilio Pérez González, La Garcineida. Estudio y edición crítica con traducción, "Euphrosyne" 31 (2003), pp. 579-81.

Cienfuegos García, Juan José, La Garcineida, Edición crítica y traducción, Sevilla, Universidad de Sevilla, 1981.

Cienfuegos García, Juan José, El aparte del teatro: de Terencio a la Garcineida, "Habis" 17 (1986), pp. 201-208.

Codoñer Merino, Carmen, La reforma gregoriana en los textos, en La reforma gregoriana y su proyección en la Cristiandad Occidental: siglos XIXII (Actas de la XXXII Semana de Estudios Medievales de Estella. 18 al 22 de julio de 2005), Pamplona, Institución Príncipe de Viana, 2006, pp. 451-476.

Constable, Giles, The Abbey of Cluny: A Collection of Essays to Mark the Eleven-Hundredth Anniversary of Its Foundation, Berlín, Lit, 2010.

Cowdrey, Herbert Edward John, The Cluniacs and the Gregorian Reform, Oxford, Oxford University Press, 1970.

Crozet, René, Le voyage de Urbain II et ses négotiations avec le clergé de France, "Revue Historique" 179 (1937), pp. 282-287.

Díaz y Díaz, Manuel Cecilio, Escritores eclesiásticos de la Alta Edad Media hispana (siglos VIII-XII), en Aldea Vaquero, Quintín; Marín Martínez, Tomás; Vives Gatell, José, (dirs.) Diccionario de Historia Eclesiástica de España II, Madrid, CSIC, 1972, pp. 849-855. 
Díaz y Díaz, Manuel Cecilio, El "Liber Sancti Iacobi", Situación de los problemas, "Compostellanum" 32 (1987), pp. 359-442.

Defourneaux, Marcelin, Les français en Espagne aux XIe et XIIe siècles, París, Presses Universitaires de France, 1949.

Dolbeau, François, Maurilio Pérez, La Garcineida. Estudio y edición crítica con traducción, "Archivum Latinitatis Medii Aevi (Bulletin du Cange)" 59 (2001), pp. 325-330.

Duby, Georges, Economie domaniale et économie monétaire: Le budget de l'abbaye de Cluny entre 1080 et 1155, "Annales. Économies, Sociétés, Civilisations" 7 (1952), pp. 154-171.

Dümmler, Ernst (ed.), MGH Libelli de lite 1, Hannover, Hahn, 1891.

Erdmann, Carl, Mauricio Burdino (Gregório VIII), Coimbra, Universidade de Coimbra, 1940.

Falque, Emma, Los autores de la "Historia Compostelana", "Habis" 15 (1984), pp. 157-171.

Férotin, Marius, Une lettre inédite de saint Hugues, abbé de Cluny, à Bernard d'Agen, archevêque de Tolède (1087), "Bibliothèque de l'école des chartes" 61 (1900), pp. 339-345.

Férotin, Marius, Complément de la lettre de Saint-Hugues, abbé de Cluny, à Bernard d'Agen, archevêque de Tolède, "Bibliothèque de l'école des chartes" 63 (1902), pp. 682-686.

Ferrari, Ángel, El cluniacense Pedro de Poitiers y la "Chronica Adefonsi Imperatoris" y el Poema de Almería, "Boletín de la Real Academia de la Historia" 153 (1963), pp. 153-204.

Fletcher, Richard, Las Iglesias del Reino de León y sus relaciones con Roma en la Alta Edad Media hasta el Concilio IV de Letrán de 1215, en Fernández Catón, José María (dir.), El Reino de León en la Alta Edad Media VI, León, Centro de Estudios e Investigación San Isidoro, 1994, pp. 459-495.

Fodale, Salvatore, Comes et legatus Siciliae. Sul privilegio di Urbano II e la pretesa Apostolica Legazia dei Normanni di Sicilia, Palermo, Universitá di Palermo, 1970.

Fornasari, Giuseppe, Tra assestamento disciplinare e consolidamento istituzionale: un'interpretazione del pontificato di Urbano II, en Kolmer, Lothar; Segl, Peter (eds.), Regensburg, Bayern und Europa: Festschrift für Kurt Reindel zum 70, Regensburgo, Universitätsverlag Regensburg, 1995, pp. 213-228.

Fornés Pallicer, María Antonia, Enunciació, estil directe i estil indirecte a la Garcineida, en Artigas, Esther (ed.), Homenatge a Josep Alsina. Actes del Xè Simposi de la Secció Catalana de la SEEC, vol. II, Tarragona, Sociedad Española de Estudios Clásicos, 1992, pp. 279-283. 
Francke, Karl (ed.), MGH Libelli de lite 2, Hannover, Hahn, 1892.

Führmann, Horst, Papst Urban II. und der Stand der Regularkanoniker, Múnich, Bayerischen Akademie der Wissenschaften, 1984.

Gambra Gutiérrez, Andrés, Alfonso VI y la exención de las diócesis de Compostela, Burgos, León y Oviedo, en Estudios sobre Alfonso VI y la reconquista de Toledo. Actas del II Congreso Internacional de Estudios Mozárabes (Toledo, 20-26 Mayo 1985), Vol. II, Toledo, Instituto de Estudios Visigótico-Mozárabes, 1988.

Gambra Gutiérrez, Andrés, Alfonso VI: cancillería, curia e imperio, León, Centro de Estudios e Investigación San Isidoro, 1997.

García-Villoslada, Ricardo, La poesía rítmica de los goliardos medievales, Madrid, Fundación Universitaria Española, 1975.

González Fernández, Martín, Juan de Salisbury y los Goliardos, "Revista española de filosofía medieval" 11 (2004), pp. 213-226.

González Palencia, Ángel, El arzobispo Don Raimundo de Toledo, Barcelona, Iglesia Nacional Española, 1942.

González Vega, Felipe, Maurilio Pérez, La Garcineida. Estudio y edición crítica con traducción (León, 2001), "Veleia" 18-19 (2001-2002), pp. 527-532.

Gossman, Francis, Pope Urban II and Canon Law, Washington, Catholic University of America, 1960.

Goulburn, Edward M.; Symonds, Henry, The Life, Letters, and Sermons of Bishop Herbert de Losinga, Oxford, Parker, 1878.

Guenée, Bernard, Histoire et culture historique dans Occident medieval, París, Aubier, 1980.

Gutiérrez Iglesias, María Rosa, Una bula de Urbano II. Su trascendencia en el seno de una comunidad de aldeas, “Aragón en la Edad Media” 10-11 (1993), pp. 407-416.

Hamilton, Louis I., Memory, Symbol, and Arson: Was Rome "Sacked" in 1084?, "Speculum" 78/2 (2003), pp. 378-399.

Healy, Patrick, The Chronicle of Hugh of Flavigny: Reform and the Investiture Contest in the Late Eleventh Century, Londres, Ashgate, 2006.

Hermann, Klaus-Jürgen, Das Tuskulanerpapsttum (1012-1046), Stuttgart, Hiersemann, 1973.

Higashi, Alejandro, Revisitación al Tractatus [...] de reliquiis preciosorum martirum Albini atque Rufini o Garcineida: género e innovación, en Company Company, Concepción; González, Aurelio; Walde Moheno, Lilian von der (eds.), Discursos y representaciones en la Edad Media, Actas de las VI Jornadas Medievales, México, Universidad Nacional Autónoma de México, 1999, pp. 51-85. 
Higashi, Alejandro, Horacio lírico y el Tractatus de reliquiis preciosorum martirum Albini atque Rufini o Garcineida, "Nueva Revista de Filología Hispánica" 49 (2001), pp. 493-504.

Higashi, Alejandro, Tendencias en la edición crítica de textos latinos medievales, "Revista de literatura medieval" 18 (2006), pp. 263-307.

Hilka, Alfons; Schumann, Otto; Bischoff, Bernhard, Carmina Burana I, Heidelberg, Carl Winter, 1930.

Hofmeister, Adolf (ed.), MGH Scriptores rerum Germanicarum 45, Hannover, Hahn, 1912.

Hofmeister, Adolph (ed.), MGH Scriptores (in folio) 30-2, Leipzig, Hiersemann, 1934.

Holkotte, Heinrich, Hugo Candidus, ein Freund und Gegner Gregors VII, Münster, Theissing, 1903.

Holtzmann, Walther, Die Unionsverhandlungen zwischen Kaiser Alexios I. und Papst Urban II. im Jahre 1089, "Byzantinishce Zeitschrift" 28 (1928), pp. 38-67.

Hoskier, Herman Charles (ed.), Bernard of Cluny, De Contemptu Mundi, Londres, Quaritch, 1929.

Houben, Hubert, Urbano II e i Normanni (Con un 'appendice sull' itinerario del papa nel Sud), en Houben, Hubert (ed.), Mezzogiorno normanno-svevo. Monasteri e castelli, ebrei e musulmani, Nápoles, Liguori 1996, pp. 134-139.

Hüls, Rudolf, Kardinäle, Klerus und Kirchen Roms, 1049-1130, Tubinga, Max Niemeyer, 1977.

Hunt, Noreen, Cluny under S. Hugh (1049-1109), Notre Dame, University of Notre Dame Press, 1968.

Isla Frez, Amancio, La historiografía en la época de Alfonso VI: la llamada Historia Silense, en Alfonso VI y su legado, en Actas del Congreso Internacional, Sahagún, 29 de octubre al 1 de noviembre de 2009: IX Centenario de Alfonso VI (1109-2009), León, Diputación de León, 2012, pp. 81-88.

Jordan, Karl, Zur päpstlichen Finanzgeschichte im 11. und 12. Jahrhundert, "Quellen und Forschungen aus Italienischen Archiven und Bibliotheken" 25 (1933-4), pp. 61-104.

Kehr, Paul, Due documenti pontifici illustranti la storia di Roma negli ultimi anni del secolo XI, "Archivio della società romana di storia patria" 23 (1900), pp. 277-283.

Kehr, Paul Cómo y cuándo se hizo Aragón feudatario de la Santa Sede, "Estudios de Edad Media de la Corona de Aragón" 1 (1945), pp. 285-326.

Kühl, Henriette, Zur Überlieferung und Rezeption der Weltchronik Richards von Cluny, en Engels, Peter (ed.) Aus Überrest und Tradition. Fests- 
chrift für Anna-Dorothee von den Brincken, Pegnitz, Europaforum, 1999, pp. 73-92.

Kuttner, Stephan, Urban II and the Doctrine of Interpretation: A Turning Point?, "Studia Gratiana" 15 (1972), pp. 53-85.

Lacombe, Claude, Jerónimo de Perigueux (1060?-1120) obispo de Valencia y de Salamanca: un monje-caballero en la Reconquista, Salamanca, Universidad Pontificia de Salamanca, 2000.

Lapeña Paúl, Ana Isabel, Sancho Ramírez, rey de Aragón (¿1064?-1094) y rey de Navarra (1076-1094), Gijón, Trea, 2004.

Leclercq, Jean, The Monastic Crisis of the Eleventh and Twelfth Centuries, en Hunt, Noreen, (ed.), Cluniac Monasticism in the Central Middle Ages, Camden, Hichon Books, 1971, pp. 217-237.

Lehmann, Paul Joachim Georg, Die Parodie im Mittelalter, Múnich, Drei Masken, 1922.

Lida de Malkiel, María Rosa, La Garcineida de García de Toledo, "Nueva Revista de Filología Hispánica" 7 (1953), pp. 246-258.

Longo, Umberto, Yawn, Lila (eds.), Framing Clement III, (Anti)Pope, 10801100, "Reti Medievali" 13/1 (2012), pp. 115-208.

López Ferreiro, Antonio, Historia de la Santa A.M. Iglesia de Santiago de Compostela, Santiago de Compostela, Imprenta del Seminario Conciliar, 1898.

Lunt, William Edward, Financial Relations of the Papacy with England, to 1327, Cambridge, Mediaeval Academy of America, 1939.

Mansi, Giovanni Domenico, Sacrorum conciliorum nova, et amplissima collectio, Venecia, Antonio Zatta, 1778.

Martínez, H. Salvador, Vasallaje castellano-leonés a Cluny: de Fernando I a Alfonso VI, en Fernández González, María Etelvina, Pérez Gil, Javier (coords.), Alfonso VI y su época. Los precedentes del reinado (9661065), León, Universidad de León, 2007, pp. 147-187.

Melve, Leidulf, Inventing the Public Sphere. The Public Debate during the Investiture Contest (c. 1030-1122), Leiden, Brill, 2007.

Meyer, Paul, Les manuscrits français de Cambridge. III, Trinity College, "Romania" 32 (1903), pp. 18-120.

Migne, Jacques-Paul (ed.), Patrologia Latina, t. 145, París, Garnier, 1853.

Migne, Jacques-Paul (ed.), Patrologia Latina, t. 148, París, Garnier, 1878.

Migne, Jacques-Paul (ed.), Patrologia Latina, t. 151, París, Garnier, 1881.

Migne, Jacques-Paul (ed.), Patrologia Latina, t. 157, París, Garnier, 1899.

Mínguez, José María, Alfonso VI: poder, expansión y reorganización interior, Madrid, Ariel, 2000.

Montaner Frutos, A.; Escobar Chico, Á. (eds.), Carmen Campidoctoris o Poema latino del Campeador, Madrid, Sociedad Estatal España Nuevo Milenio, 2001. 
Moralejo, José Luis, Literatura hispano-latina (siglos V-XVI), en Díez Borque, José María (ed.), Historia de las literaturas hispánicas no castellanas, Madrid, Taurus, 1980, pp. 94-137.

Moralejo, José Luis, Latín y cultura en la España medieval, "Studium Ovetense" 12 (1984), pp. 7-26.

Noonan Jr., John T., The Power to Choose, "Viator" 4 (1975), pp. 419-434.

Ott, John S., Urban Space, Memory, and Episcopal Authority: The Bishops of Amiens in Peace and Conflict, 1073-1164, "Viator" 31 (2000), pp. 43-77.

Paulot, Lucien, Un pape français: Urbain II, París, Víctor Lecoffre, 1903.

Payer, Pierre J. (ed.), Book of Gomorrah: An Eleventh Century Treatise against Clerical Homosexual Practise, Waterloo, Wilfrid Laurier University Press, 1982.

Pérez González, Maurilio, Religión y política a fines del siglo XI: la Garcinei$d a$, "Analecta malacitana electrónica" 6 (2000), <http://www.anmal. uma.es/numero6/Maurilio.htm> [consulta: 12/06/2012].

Pérez González, Maurilio, La Garcineida. Estudio y edición crítica con traducción, León, Universidad de León, 2001.

Pérez González, Maurilio, De nuevo sobre la Garcineida, "Cuadernos de filología clásica: Estudios latinos" 24/2 (2004), pp. 249-255.

Pérez de Urbel, Justo; González Ruiz-Zorrilla, Atilano (eds.), Historia Silense: edición crítica e introducción, Madrid, CSIC, 1959.

Pertz, Georg Heinrich (ed.), MGH Scriptores (in folio) 5, Hannover, Hahn, 1843.

Pertz, Georg Heinrich (ed.), MGH Scriptores (in folio) 8, Hannover, Hahn, 1848.

Pertz, Georg Heinrich (ed.), MGH, Leges I-2, Hannover. Hahn, 1887.

Pflugk-Harttung, Julius von, Iter Italicum, Stuttgart, Kohlammer, 1883.

Pepin, Ronald E., Scorn for the World: Bernard of Cluny's De Contemptu Mundi, East Lansing, Colleagues, 1991.

Poole, Reginald L., Benedict IX and Gregory VI, "Proceedings of the British Academy, London" 8 (1917), pp. 199-235.

Quintana Prieto, Augusto, Sampiro, Alón y Arnaldo. Tres obispos de Astorga, cronistas del reino de León, en León medieval. Doce estudios. Ponencias y comunicaciones presentadas al coloquio "El reino de León en la Edad Media”, León, Colegio Universitario de León, 1978, pp. 59-68.

Ramackers, Johannes, Analekten zur Geschichte des Reformpapsttums und der Cluniazenser, "Quellen und Forschungen aus Italienischen Archiven und Bibliotheken" 23 (1931), pp. 22-52.

Reglero de la Fuente, Carlos Manuel, Cluny en España. Los prioratos de la provincia y sus redes sociales (1073-ca. 1270), León, Centro de Estudios e Investigación San Isidoro, 2008. 
Rico, Francisco, Las letras latinas del siglo XII en Galicia, León y Castilla, "Ábaco: Estudios sobre literatura española" 2 (1969), pp. 9-91.

Rigg, Arthur George, Golias and other pseudonyms, "Studi medievali" 18 (1977), pp. 65-109.

Rivera Recio, Juan Francisco, El Arzobispo de Toledo Don Bernardo de Cluny (1086-1124), Roma, Iglesia Nacional Española, 1962.

Rivera Recio, Juan Francisco, La Iglesia de Toledo en el siglo XII (10861208), Roma, Iglesia Nacional Española, 1966-1976.

Robinson, Ian Stuart, Authority and Resistance in the Investiture Contest. The Polemical Literature of the Late Eleventh Century, Nueva York, Holmes \& Meier Publishers, 1978.

Robinson, Ian Stuart, Periculosus Homo: Pope Gregory VII and Episcopal Authority, "Viator" 9 (1978), pp. 103-131.

Robinson, Ian Stuart, The Papacy, 1073-1198: Continuity and Innovation, Cambridge, Cambridge University Press, 1990.

Rolker, Christof, Canon Law and the Letters of Ivo of Chartres, Cambridge, Cambridge University Press, 2010.

Romero de Lecea, Carlos; Gerra Campos, José; Filgueira Valverde, José (eds.), Libro de la Peregrinación del Códice Calixtino, Madrid, Joyas Bibliográficas, 1971.

Sala, Luis, Los autores de la "Historia Compostelana", "Hispania" 3 (1943), pp. 16-69.

Schnack, Ingeborg, Richard von Cluny, seine Chronik und sein Kloster in den Anfängen der Kirchenspaltung von 1159: Ein Beitrag zur Geschichte der Anschauungen von Kardinalskolleg und Papsttum im 12. und 13. Jahrhundert, Berlín, Ebering, 1921.

Sereno, Cristina, Le diverse anime della "riforma", "Reti Medievali-Repertorio" 10/1 (2006), <http://fermi.univr.it/rm/repertorio/rm_cristina_sereno_la_riforma.html> [consulta: 15/11/2012].

Sereno, Cristina, Cluny, "Reti Medievali-Repertorio" 10/2 (2007-2008), $<$ http://fermi.univr.it/rm/repertorio/sereno_cluny.html> [consulta: $15 / 11 / 2012]$.

Serrano, Luciano, El Obispado de Burgos y Castilla primitiva: desde el siglo V al XIII, Madrid, Instituto de Valencia de Don Juan, 1935.

Smith, John James, A Catalogue of Manuscripts in the Library of Gonville and Caius College, Cambridge, Cambridge University Press, 1849.

Sommerville, Robert, Urban II's Privilege from April 16, 1097 for Hugh of Cluny and His Brothers, en Ascheri, Mario (dir.), ¿Ins wasser geworfen und Ozeane durchquerf? Festschrift für Knut Wolfgang Nörr, Colonia, Böhlau, 2003, pp. 967-977. 
Stroll, Mary, Symbols As Power: The Papacy Following the Investiture Contest, Leiden, Brill, 1991.

Stroll, Mary, Calixtus II (1119-1124): A Pope Born to Rule, Leiden, Brill, 2004.

Strongman, Sheila, John Parker's Manuscripts: An Edition of the Lists in Lambeth Palace MS 737, "Transactions of the Cambridge Bibliographical Society" 7/1 (1977), pp. 1-27.

Sydow, Jürgen, Untersuchungen zur kurialen Verwaltungsgeschichte im Zeitalter des Reformpapsttums, "Detsches Archiv" 11 (1955), pp. 18-73.

Thomson, Rodney M., Tractatus Garsiae, or The Translation of the Relics of SS. Gold and Silver, Leiden, Brill, 1973.

Urbieto Arteta, Antonio (ed.), Colección diplomática de Pedro I de Aragón y Navarra, Zaragoza, CSIC, 1951.

Ubieto Arteta, Antonio (ed.), Crónicas anónimas de Sahagún, Zaragoza, Anubar, 1987.

Vielliard, Jeanne, Le guide du pelerin de Saint-Jacques de Compostelle, Mâcon, Protat, 1963.

Waitz, Georg (ed.), MGH Scriptores (in folio) 26, Hannover, Hahn, 1882.

Webb, Clement Charles Julian (ed.), Ioannis Saresberiensis episcopi Carnotensis Policratici, Oxford, Clarendon, 1909.

Weber, Edwin J., Comedy as Satire in Hispano-Arabic Spain, "Hispanic Review" 26 (1958), pp. 1-11.

Werckmeister, Otto Karl, Cluny III and the Pilgrimage to Santiago de Compostela, "Gesta" 27/1-2 (1988), pp. 103-112.

Wright, Roger, La "Garcineida": Estudio y edición crítica con traducción by Maurilio Pérez González, "Speculum" 78/3 (2003), pp. 976-979.

Wright, Thomas (ed.), The Anglo-Latin Satirical Poets and Epigrammatists of the Twelfth Century, Londres, Longman, 1872.

Yunck, John. A., Economic Conservatism, Papal Finance, and the Medieval Satires on Rome, "Mediaeval Studies" 23 (1961), pp. 334-351.

Yunck, John A., The Lineage of Lady Meed. The Development of Mediaeval Venality Satire, Notre Dame, University of Indiana Press, 1963.

Zema, Demetrius B., Economic Reorganization of the Roman See during the Gregorian Reform, "Studi Graziani" 1 (1947), pp. 155-175.

Ziese, Jürgen, Wibert von Ravenna: der Gegenpapst Clemens III (1080-1100), Stuttgart, Hiersemann, 1982.

Fecha de recepción del artículo: junio 2012

Fecha de aceptación y versión final: noviembre 2012 